\title{
Boris Vian oder die Literatur im Jazz der Massenkultur
}

Wenden wir uns nun dem literarischen Werk eines der aus meiner Sicht sicherlich aus heutiger Perspektive interessantesten französischen Autoren zu, Boris Vian, dessen vielgestaltiges Schaffen eine Unzahl von Anschlussmöglichkeiten und Rekontextualisierungen erlaubt, die mit den im Kontext unserer Vorlesung beobachteten Entwicklungen in Verbindung zu bringen sind! Zwar ist die große Begeisterung um Boris Vian, die im Kontext von 1968 in Frankreich wiederauflebte, längst verklungen und auch die deutschsprachige Leserschaft ist nicht mehr ganz so euphorisch gestimmt, selbst wenn es eine wohlfeile und liebevoll gemachte Ausgabe in deutscher Sprache gibt. Doch ist Boris Vian nicht völlig in der Versenkung verschwunden, sondern nach wie vor weit mehr als ein literarischer Geheimtipp.

Sie werden mich fragen, warum ich überhaupt mit diesem französischen Schriftsteller unseren Parcours durch die Literaturen im Zeichen der Postmoderne beginne, zählte Boris Vian doch eher zu den Exponenten eines Existenzialismus in den Bars und Bauchläden der französischen Nachkriegszeit. Dem lässt sich entgegenhalten, dass etwa der US-amerikanische Literaturkritiker Leslie Fiedler, der wohl die entscheidende Stimme war, welche den Begriff der „Postmoderne“ in die Literaturwissenschaft einbrachte, Boris Vian sehr wohl zu den Vertretern einer literarischen Praxis zählte, die er im Zeichen des neuen Begriffs sah. Ich glaube schon, dass Leslie Fiedler in seinem übrigens in der US-amerikanischen Ausgabe des Playboy veröffentlichten Aufsatz Cross the Border - Close the Gap! ${ }^{1}$ den Kern der Sache trifft, wenn er darauf hinweist, dass Boris Vian für eine sehr lange Zeit ein völlig isoliertes Phänomen innerhalb der französischen Literatur darstellte.

Der Playboy war deshalb ein idealer Veröffentlichungsort, weil damit die Trennung zwischen Hochkultur (der die Literaturwissenschaft angehört) und Massenkultur unterlaufen wurde, was übrigens für den Aufsatz selbst gilt, wirkte er doch breit hinein in die damaligen Debatten rund um eine neue Ästhetik. Fiedler sah Boris Vian im Kontext einer literarischen Entwicklung, in der die Autoren des Nouveau Roman eine allzu seriöse, allzu ernste Literaturkonzeption betrieben hätten. Dies aber hielt der US-Amerikaner offensichtlich für allzu langweilig. Kein Wunder also, dass der französische Literat und Trompeter gerade von

1 Vgl. Fiedler, Leslie A.: Cross the Border - Close the Gap. In: Playboy 12 (1969). Später in Buchform veröffentlicht von Fiedler, Leslie A.: Cross the Border - Close the Gap. New York: Stein \& Day 1972.

Ә Open Access. () 2021 Ottmar Ette, publiziert von De Gruyter. (c) BBY-NC-ND Dieses Werk ist lizensiert unter einer Creative Commons Namensnennung - Nicht-kommerziell - Keine Bearbeitung 4.0 International Lizenz. https://doi.org/10.1515/9783110703450-026 
Fiedler lange nach Boris Vians Tod für die Postmoderne reklamiert wurde - und wir werden sehen, ob es gute Gründe hierfür gibt: Fiedler selbst nennt herzlich wenig Anhaltspunkte. Aber es ging ihm ja auch nur um das Aufmischen einer verkrusteten Literaturwissenschaft und Literaturkritik, welche die neuen Entwicklungen nicht habe wahrnehmen wollen.

Leslie Fiedler nannte Boris Vian in seinem berühmten Playboy-Aufsatz von 1968 immerhin einen Amerikaner - gemeint ist ein US-Amerikaner - im Geiste, was aber allein wohl noch nicht ausreicht, um den französischen Autor der Postmoderne zuzuschlagen, ganz abgesehen davon, dass die Postmoderne sicherlich kein ausschließlich oder überwiegend US-amerikanisches Phänomen ist. Aber so sind sie nun mal, die US-Amerikaner ... Zweifellos gibt es eine Vielzahl von Beziehungen zwischen Boris Vian und der Kultur der Vereinigten Staaten, worauf wir noch kommen werden. So tauchten auch immer wieder Bezeichnungen für Boris Vian auf wie „Le cowboy de Normandie“ oder ähnliches. Ich komme darauf zurück.

Übrigens heizte Leslie Fiedler auch in der alten Bundesrepublik die Debatte um die Postmoderne an, hielt er doch noch im Sommer 1968 an der Albert Ludwigs-Universität in Freiburg im Breisgau diesmal im Rahmen eines seriösen Symposions einen vieldiskutierten Vortrag, der letztlich seine Thesen von Cross the Border - Close the Gap! wiederholte. Seine Ausrufung einer literarischen Postmoderne bei gleichzeitiger Toterklärung der Moderne löste viel Rauschen im Blätterwald der bundesdeutschen Feuilletons aus. Doch sind all dies aus heutiger Perspektive Anekdoten rund um die historische Durchsetzung eines Postmoderne-Begriffs, in dem es weniger um theoretische Schärfe als um größtmögliche Breitenwirkung und ein wenig Provokation ging. Beschäftigen wir uns lieber mit Boris Vian und dabei wie gewohnt zunächst mit einigen Biographemen im Leben jenes Schriftstellers, den Fiedler kurzerhand als Vertreter einer US-amerikanischen Postmoderne nominierte!

Boris Vian wurde am 10. März 1920 in Ville d’Avray im Département Seineet-Oise geboren und starb in Paris am 23. Juni 1959. Als Sohn eines mit Goldgeschäften in den zwanziger Jahren zunächst reich und in der Weltwirtschaftskrise wieder verarmten Vaters las Boris seit seinem fünften Lebensjahr französische Klassiker, spielte Schach und beherrschte mehrere Musikinstrumente, darunter auch die Trompete, die ihn später berühmt-berüchtigt werden ließ. Seine Spielkameraden waren keine Geringeren als Yehudi Menuhin (dessen Eltern die Villa der Vians abgekauft hatten, die verarmt in das Gärtnerhäuschen des Anwesens zogen) und François Rostand. Getrübt wurde diese fröhliche Kindheit durch eine schwere Diphtherie im Alter von zwölf Jahren, welche eine Herzmuskelschwäche nach sich zog. Der junge Boris besuchte das Pariser Lycée Condorcet und damit eines der renommiertesten Pariser Gymnasien, wo er verfrüht und mit Sondergenehmigung sein Abitur ablegte. 


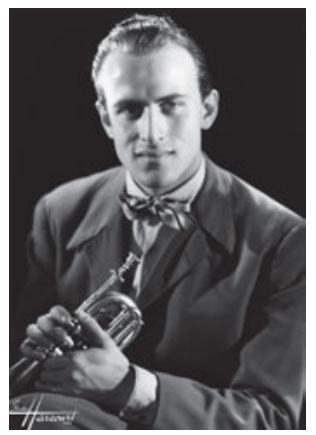

Abb. 101: Boris Vian (Ville-d'Avray im Westen von Paris, 1920 Paris, 1959).

Als Fünfzehnjähriger erkrankte der Jugendliche an Typhus. Sein schlechter Gesundheitszustand verlangte ihm fortan Rücksichten ab, die einzuhalten ihm stets Schwierigkeiten bereiten sollten. 1940 wich die Familie dem deutschen Blitzkrieg aus, 1941 heiratete er und legte 1942 das Ingenieursexamen ab mit der Fachrichtung Metallurgie. Im besetzten Paris arbeitete er zunächst in der Association Française de Normalisation, nach dem Ende der deutschen Besetzung ab 1946 beim Office du Papier, dem Verband der Papier- und Pappindustrie. Im Kontext der „normalisation“ entsteht das Projekt einer Normierung französischer Flüche für Durchschnittsfranzosen - seine ersten literarischen Texte sind bereits erschienen.

Bereits 1942 gründete er mit Claude Abadie eine Jazzband, deren Erfolg beachtlich war. Vian, der „trompettiste“, wurde als „Prinz Boris“ in den entstehenden existentialistischen Zirkeln von Saint-Germain-des-Prés der vierziger Jahre gefeiert. 1943 erschien sein wohl erster Roman Aufruhr in den Ardennen, der jedoch nur im Freundeskreis gelesen wurde. Nach der Occupation tritt Vian unter anderem in Jazzkonzerten für die US-Armee auf; erste auch internationale Erfolge des Orchesters von Abadie stellen sich ein. Zugleich nimmt seine literarische Karriere Formen an. Vian gehörte später einige Zeit zum engeren Zirkel um Jean-Paul Sartre, der ihn freilich durch die Liebelei mit Vians Frau sowie durch sein elitäres Gehabe abstieß, so dass Vian auch seine seit Juni 1946 regelmäßige Kolumne Chronique du menteur in Sartres Temps Modernes einstellte. Doch „Prinz Boris“ übersetzte aus dem Amerikanischen, schrieb Jazzkritiken und spielte nachts als unterhaltsamer, wenn auch nicht unbedingt begnadeter Jazztrompeter auf.

Boris Vians Aktivitäten waren in jenen Jahren vielfältig und erstaunen durch ihre unverklemmte Lust an allem, was ihm begegnete. Er beschäftigte sich mit Mathematik und Technik, Poesie und Philosophie im gleichen Maße, experimentierte mit allerlei technischen Geräten, erfand elektronische Reim- und Dichtungsmaschinen und pendelte unverdrossen zwischen den Berufen Ingenieur, 
Dichter, Musiker, Kritiker, Schauspieler und Sänger hin und her. Erst 1947 gab er seinen Ingenieurberuf endgültig auf und hielt sich mit seinen Übersetzungen und literarisch-journalistischen Artikeln etwa für die wichtige Zeitschrift Combat über Wasser. Auch als Verfasser von allerlei Chansons machte er sich einen Namen. er hoffte, nach Veröffentlichung seines Romans L'Ecume des jours im Jahr 1946 einige Kapitel erschienen als Vorabdruck in Sartres Zeitschrift Les Temps Modernes - seinen Lebensunterhalt als Schriftsteller verdienen $\mathrm{zu}$ können. Im selben Jahr 1946 erregte aber seine angebliche Übersetzung eines fiktiven afroamerikanischen Autors namens Vernon Sullivan mit dem Titel J'irai cracher sur vos tombes einen Skandalerfolg; als Verfasser dieses Sex-and-Crime-Romans wurde er vor Gericht gestellt und wegen Unmoral angeklagt, doch ein Amnestiegesetz kommt ihm zu Hilfe. Die französische Justiz setzt jedoch nach und verurteilt ihn zu einer hohen Geldstrafe sowie später noch zu zwei Wochen Gefängnis, was jedoch umgehend amnestiert wird. Mit seinen nachfolgenden „Sullivans“ war er in Frankreich weniger erfolgreich, hatte sich aber einem Genre der US-amerikanischen Massenkultur angenähert, was ihm ganz nebenbei die späte Bewunderung von Leslie Fiedler eintragen sollte. Boris Vians „Sullivans“ haben in den USA durchaus Erfolg, was der französische Autor befriedigt zur Kenntnis nimmt.

Anfang der fünfziger Jahre gab Vian das Schreiben von Romanen auf. Er konnte nicht ahnen, dass Der Schaum der Tage schon bald nach seinem Tod im Jahr 1959 zum Kultbuch einer ganzen Generation werden sollte. Aber auch seine anderen, weniger bekannten Romans wurden neu aufgelegt und wirkten später gerade durch ihre zahlreichen Anleihen aus Schreibformeln der Massenkultur wie Zeugnisse eines Schriftstellers, der verfrüht auf ein Schließen jenes „Gap“ zwischen ,Hoher Literatur ‘ und einer davon strikt getrennten Massenkultur aus war.

Im Juni 1952 wird er auf den Spuren unseres Alfred Jarry Mitglied des Collège de Pataphysique in der Eigenschaft als „équarrisseur de première classe“: Boris Vian weiß sich in der Tradition dieses großen Vorläufers der historischen Avantgarden. Und eine ähnliche Vorläuferrolle könnte man ihm in der Tat nicht absprechen. Er steigt rasch in der Pataphysik unter Raymond Queneau auf, veröffentlicht in den Cahiers de Pataphysique und nimmt an pataphysischen Wallfahrten teil. Seine kurzen Sketche und Texte für Rundfunk wie Theater hatten zu seinen Lebzeiten ebenfalls nur geringen Erfolg. Seine zahlreichen Gedichte erschienen in verschiedenen Sammlungen wie etwa Je voudrais pas crever von 1953. 1954 wurde Vian von Jacques Canetti, übrigens dem Bruder von Elias Canetti, zur Zusammenstellung von Jazzreihen und Programmfolgen der Jazzplattenabteilung bei der Firma Philips engagiert. Auf diesem Gebiet wurde endlich seine Kompetenz nicht länger hinterfragt. Vian arbeitete als Übersetzer von Raymond Chandler und war für die Vermittlung der US-Kultur ebenso als Musiker wie als Musikkritiker beteiligt. Mitte der fünfziger Jahre schrieb Vian den ersten französischen Rock 'n' Roll; 
für das Genre setzte er sich auch bei Schallplattenfirmen erfolgreich ein. Berühmt wurde er auch durch sein von ihm selbst gesungenes pazifistisches Chanson Le Déserteur in Zeiten, in welchen Frankreich im Chaos seiner Kolonialkriege zu versinken drohte und die Justiz auf ihn gehetzt wurde.

Doch Vians Gesundheitsprobleme machten sich in der zweiten Hälfte der fünfziger Jahre wieder verstärkt bemerkbar. Das Multitalent - das auch einige Gemälde hinterließ und verschiedene Opern verfasste - und Enfant terrible der französischen Literaturszene verstarb an einem Herzinfarkt während einer privaten Vorführung der Verfilmung seines Skandalerfolges Auf Eure Gräber werde ich spucken. Er war mit letzterer in keiner Weise einverstanden und wehrte sich gegen deren Realisierung: gleichsam ein letztes Statement gegenüber einer Gesellschaft, die sein kritisches Potenzial nicht frühzeitig genug erkannt und verstanden hatte. Boris Vian, der auch am Théâtre de l'Euvre tätig war, darf mit Recht als einer der prominentesten Nachfolger des legendären Alfred Jarry gedeutet werden.

Wenn wir uns also mit Boris Vian beschäftigen, so haben wir es mit einem Künstler zu tun, der die verschiedensten Ausdrucksformen in Leben wie Kunst verwendete und den allein auf den Bereich der Literatur festzulegen nicht statthaft ist. Er schrieb Romane und Gedichte, verfasste Essays und übersetzte, konzipierte Drehbücher und schrieb Opern, entwarf Maschinen und schuf ein graphisches Werk, das erst spät den Weg zu seinem Publikum fand. Er beeindruckte ebenso als Musiker wie als Musikkritiker, setzte sich für die entstehende Popkultur ein und sang pazifistische Chansons, war ein Hansdampf in allen Gassen und breiten Alleen der Kultur, verband aber all diese Ausdrucksformen auf überzeugende Weise miteinander und ließ eine Trennung zwischen Hoch- und Populärkultur nicht gelten. Gerade in dieser Vielfalt von Ausdrucksmitteln und künstlerischen Äußerungsweisen liegt der Schlüssel zu Boris Vians Verständnis. Und doch wollen wir uns seinem Gesamtwerk zunächst vom Bereich der Literatur her annähern und dabei einen Einstieg benutzen, der seinen - abgesehen vom Skandalerfolg J'irai cracher sur vos tombes - heute sicherlich bekanntesten und meistgelesenen Roman betrifft: den wenig umfangreichen, aber sehr symbolträchtigen Erzähltext L'Ecume des jours.

Dieser Roman geht wohl auf ein 1945 konzipiertes Projekt zurück und dürfte wohl zwischen März und Mai 1946 niedergeschrieben worden sein. Vian arbeitete damals beim Office Central de Répartition de Produits Industriels und schrieb in seinem Büro sein Buch zu Ende - das nenne ich mal eine effiziente Büro-Graphie! Dieser Hintergrund wirft vielleicht schon ein erstes Licht auf seinen Bezug zum bürgerlichsten aller Werte, dem Wert der Arbeit, der für Boris Vian angesichts seiner enormen Arbeitsleistung im künstlerischen Bereich sicherlich große Wichtigkeit besaß. Jedenfalls ist ein Dienstzimmer - das wissen wir von vielen Schriftstellern - ein perfekter Ort, um einen Roman abzuschließen. 
Ein gut zweihundertseitiges Manuskript liegt Jean-Paul Sartre und Simone de Beauvoir bald vor, und sie veröffentlichen Auszüge daraus im Oktober des Jahres 1946 in ihrer berühmten Zeitschrift Les Temps Modernes. Es handelt sich zum damaligen Zeitpunkt freilich um eine Manuskriptfassung, in der aus heutiger Sicht wesentliche Bestandteile fehlen. Nicht zuletzt all jene kitzeligen Anspielungen auf Sartre und Beauvoir, welche die heutige Leserschaft so sehr entzücken. In der Nouvelle Revue Française erscheint der Band dann im März beziehungsweise April 1947 in der definitiven Fassung, wobei Boris Vian wohl knapp am Prix de la Pléiade vorbeisegelt. Aber so ist das nun mal ...

Vians Roman erfährt eine ganze Folge an Neuauflagen, insbesondere seit er 1963 bei Pauvert in die Collection 10/18 Eingang fand und zu einem wahren Kultbuch avancierte. Es gab mindestens eine Filmfassung von Charles Belmont und daneben im Vorfeld und Umfeld von Mai 1968 zwei Theaterfassungen, welche in Paris und Brüssel 1967 beziehungsweise 1968 uraufgeführt wurden. Der Roman erzielte durchaus eine längere Wirkung, die bis heute anhält, wobei er eine der schönsten und ergreifendsten Geschichten und mehr noch Liebesgeschichten entfaltet, die in der zweiten Hälfte des vergangenen Jahrhunderts - und das will einiges besagen - geschrieben worden sind. Wer diesen kleinen Roman einmal gelesen hat, vergisst ihn gewiss nicht mehr!

Boris Vians Roman ist in achtundsechzig mehr oder minder kurze Kapitel eingeteilt, die bisweilen eine kinoähnliche Schnitttechnik aufweisen - nicht umsonst schrieb der junge Franzose auch Drehbücher. Dabei geht dem Text nach der zärtlichen Widmung ,à mon bibi“ ein Vorwort voraus, das zwar kurz ist, aber es in sich hat. Dort lesen wir etwa, dass es in der Tat so zu sein scheint, dass die Massen stets unrecht und die Individuen recht haben. Es gebe nur zwei Dinge im Leben, die es wert seien, wirklich gelebt zu werden: nämlich die Liebe jeglicher Art mit hübschen Mädchen sowie die Musik aus New Orleans und jene von Duke Ellington.

Ich hoffe, dass die Formulierung „mit hübschen Mädchen“ nicht dazu führt, dass Sie Vian etwas vorschnell als Musterexemplar der noch nicht im Aussterben begriffenen Gattung des französischen „Chauvi“ klassifizieren. Im Übrigen kann man in Sachen Liebe dem Verfasser des Vorworts durchaus glauben, dass „de toutes les façons“ ernst gemeint ist. Ein Blick in Boris Vians sogenannte Ecrits pornographiques mag belegen, dass er sich wirklich für sehr verschiedene Arten von Liebe interessierte und vor allem nach dem darin enthaltenen Freiheitspotential Ausschau hielt. Dazu vielleicht später mehr ...

Bereits jetzt will ich aber die Tatsache erwähnen, dass auch in L'Ecume des jours Anspielungen auf den Marquis de Sade nicht fehlen. Denn der „Göttliche Marquis“ ist in der Tat bereits seit dem 19. Jahrhundert eine der wichtigsten literarischen Unterströmungen der französischen Literatur - denken Sie nur an einen 
Autor wie Flaubert. Diese Unterströmung, die sich zumeist im oberen Bereich der Bücherschränke ansiedelt, wanderte im 20. Jahrhundert langsam aus den Giftschränkchen herab und erreichte justament in den sechziger Jahren - übrigens auch im Umkreis von Roland Barthes und einigen Mitgliedern der Tel-QuelGruppe - ein breiteres Publikum. Diese graduelle Entwicklung lässt sich über einen langen Zeitraum verfolgen, ${ }^{2}$ bis der Marquis de Sade schließlich nach 1968 als Schulbuchautor Eingang fand in die „Manuels scolaires“, in die französischen Schulbücher, wenn auch in etwas entschärfter Fassung.

Jedenfalls ist eine Lektüre des „göttlichen Marquis“ einigermaßen unerlässlich, um die französische Literatur des 19. und der ersten Hälfte des 20. Jahrhunderts zu verstehen - aber auch unseren Boris Vian und dessen Relation zum Sexus. Dabei war Vian natürlich zeitgenössisch in guter Gesellschaft, denken Sie nur einmal an die US-amerikanischen Schriftsteller, an Autoren wie Henry Miller und sein Opus Pistorum, aber auch an eine Schriftstellerin wie Anaïs Nin, die wir derselben Bewegung eines vertieften Umgangs mit dem Sexus und dem erotischen Körper in der Literatur zurechnen dürfen! Auch an dieser Stelle tut sich folglich eine starke Beziehung des französischen Romanciers zu zeitgleichen Entwicklungen auf, welche die Literatur- und Kulturszene in den Vereinigten Staaten prägten.

Das zweite, worauf es im Leben ankomme, sei der Jazz aus New Orleans und Duke Ellington: Alles andere sei hässlich, ein überflüssiger Rest. $\mathrm{Zu}$ diesem gehört, wie Sie sich unschwer vorstellen können, eine ganze Menge. Aber so wissen wir schon einmal, mit welchem Ton der Roman Boris Vians einsetzen wird: mit dem Ton des Jazz und der Phrase der Liebe. Dabei verbindet sich beides schon im Namen der Geliebten und Frau Colins miteinander, in Chloé nämlich, die nicht nur ganz selbstverständlich an die Liebesgeschichte aus der Antike zwischen Daphnis und Chloe erinnert, sondern im Text auch explizit auf den Song Chloé im Arrangement von Duke Ellington bezogen wird. Literatur ist in diesem Roman also nicht nur mit der Liebe, sondern auch und vor allem mit der Musik des Jazz verwoben.

Deshalb verwundert es nicht, wenn das Vorwort auf New Orleans (einigermaßen unzutreffend) im März 1946 (einigermaßen zutreffend) datiert ist und wiederum der Roman selbst an seinem Ende paratextuell einen fiktionalisierten Zeit-Raum angibt: Memphis, 8. März 1946 und Davenport, 10. März 1946. Memphis dürfte uns dabei vielleicht an Faulkner und Davenport in jedem Fall

2 Vgl. die große Bedeutung von Lely, Gilbert: Sade. Etudes sur sa vie et sur son œuvre. Paris: Gallimard 1967; der Autor verfasste eine Vielzahl von Vorworten für die von ihm herausgegebenen Werke. 
an Jazz erinnern. Viel deutlicher kann man die eigenen Bezüge zur US-amerikanischen Kultur - gerade auch zu jenem Zeitpunkt unmittelbar nach Ende des Zweiten Weltkriegs - nicht markieren. Da ist schon vieles von jener generationellen Erleichterung und aufgestauten Lebenslust zu spüren, welche die jungen Französinnen und Franzosen nach Ende der Okkupation durch die deutschen Nationalsozialisten prägte. Jedenfalls heißt es abschließend im Vorwort, dass die Seiten, die folgen, ihre Stärke daraus bezögen, dass sie gänzlich wahr seien, denn das „Ich“ habe sie von einem zum anderen Ende frei und vollständig erfunden. Der Roman erscheine wie eine Projektion auf einen welligen und schiefen Untergrund. So wissen wir nach der Lektüre des paratextuellen Vorworts, dass wir im Bereich der Fiktionen und Projektionen sind; und auch in der Schlussmetapher des Vorworts kommt erneut die Kinometaphorik, das Filmische im literarischen Text, zum Tragen.

Colin wird schon auf der ersten Seite mit einer Filmfigur (und zwar aus Hollywood Canteen) verglichen und bereitet sich ähnlich wie eine Filmfigur im ersten Kapitel auf ihren (beziehungsweise seinen) Auftritt vor. Er schneidet sich rasch noch Augenbrauen und Wimpern zurecht, um seinem Blick etwas Rätselhaftes zu geben. Damit wird zum einen das Theaterhafte, Inszenierte und die Betonung der in den Vordergrund gerückten Oberfläche herausgearbeitet, zum anderen aber auch erwähnt, dass die Haare schnell wieder zuwachsen und Colin diese Operation recht häufig durchführen müsse.

Dieses kleine Detail ist für den gesamten Text von Bedeutung. Denn die Körperlichkeit ist nicht nur schöne glatte Oberfläche, die sorgfältig gepflegt und poliert wird, sondern zugleich und von Beginn an mit der Urgewalt eines Zuwachsens, einer Proliferation, eines Vorgangs des Wucherns verbunden, welcher im Grunde den gesamten Roman thematisch strukturiert und durchzieht. So findet man schon in der unscheinbaren Ouvertüre ein wichtiges Leitmotiv des gesamten Textes vor.

Und noch ein zweites Element wird in diesem Incipit ebenfalls deutlich: Colin besitzt das Lächeln eines Babys, eines Säuglings. Gerade an diesem ebenfalls scheinbar harmlosen Punkt wird bereits markiert, dass die Hauptfiguren des Romans, Colin und Chloé, um deren Liebe es hauptsächlich geht, letztlich ihrer Kindheit nicht entwachsen sind, im Grunde stets auch Kinder bleiben, welche unschuldig einer fremden, gefährlichen, lebensbedrohenden Welt ausgesetzt sind. Es ist die unschuldige Welt der beiden Liebenden, welche diesem Druck von außen auf Dauer nicht standhalten kann.

Colin ist in der glücklichen Lage, ein Vermögen $\mathrm{zu}$ besitzen, das es ihm erlaubt - wie es so schön im Text heißt -, nicht für die anderen arbeiten zu müssen. Unwillkürlich denkt man an Boris Vians eigene Jugend, die er in einer reich ausgestatteten Vorstadtvilla zubrachte - noch war der finanzielle Ruin 
seines Vaters in der Weltwirtschaftskrise nicht absehbar. Anders sieht die finanzielle Situation aus für seinen Freund Chick, mit dem er zwar eine Reihe von Ansichten, das Alter von einundzwanzig oder zweiundzwanzig Jahren und den literarischen Geschmack, nicht aber die finanzielle Ausstattung teilt: Chick muss arbeiten. Er hat, wie sich bald herausstellt, einen niederen, schlecht bezahlten und wenig angesehenen Beruf: Denn er ist - und wieder stellen sich Parallelen zum Leben Vians ein - Ingenieur.

Daher muss der Arme auch alle acht Tage zu seinem Onkel ins Ministerium, um bei diesem Geld zu pumpen. Chick kommt zum Essen zu Colin, der seinerseits einen neuen Koch engagiert hat, Nicolas, der vor seinem „tableau de bord“ sitzt und exquisite, nach hochkomplizierten Rezepten kreierte Speisen herstellt. Nicolas hat also einen sehr prestigeträchtigen Beruf und ist stolz darauf. Damit merken wir schon, dass sich sachte ein weiteres Strukturelement andeutet. Es ist das des „monde à l'envers“ oder wie man auch sagen würde: „le monde verlans.“ Nicolas ist der Stolz seiner Familie, während seine Nichte auf die schiefe Bahn kam, studierte sie doch - horribile dictu - Philosophie. Man kann sich sein Unheil auch selbst wählen ...

Außerdem stammt Alise auch väterlicherseits aus ärmlichen Verhältnissen, ist ihr Vater doch „Agrégé“ und Professor am Collège de France. Eine für die Familienehre eher peinliche, untergeordnete Stellung - wahrlich beklagenswert - und das im Alter von achtunddreißig Jahren! Was soll nur aus all diesen Akademikern werden! Die Welt auf dem Kopf erfasst freilich nicht alles, wohl aber die Wertigkeit der Berufe, die durchaus nicht unserem aus der Realität vertrauten Schema entsprechen. Und noch eines: Natürlich erinnert uns die hochmoderne Küche an jene Modernisierungsschübe, welche auch die Gastronomie in Frankreich nicht verschonten und denen Jacques Tati in seinem urkomischen Film Mon oncle einige Jahre später mit seiner vollautomatisierten Küche in seinen eigenen „modernen Zeiten“ ein unsterbliches Denkmal gesetzt hat. Sie kennen doch Jacques Tati? Man könnte ihn als ebenso schlaksiges filmisches Pendant neben den jungen Literaten Boris Vian stellen.

Chick ist nicht so gebildet: Er kennt Nicolas' gastronomischen Säulenheiligen Gouffé nicht, was er aber sofort einräumt, indem er selbst erklärt, er kenne außerhalb von Jean-Sol Partre nicht viel. Der kleine Dreher im Namen ist so herrlich, dass ich vor langen Jahren bei einem Vortrag angesichts zahlreicher Bewunderer des existenzialistischen französischen Philosophenehepaares der allzu großen Versuchung nicht widerstehen konnte, statt Jean-Paul Sartre eben Jean-Sol Partre zu sagen. Wie dem auch immer sei: Der ungebildete Chick hat die hübsche Nicht von Nicolas, die leider akademische Alise, neulich bei einer Veranstaltung von Partre kennengelernt, ist doch auch sie als Philosophiestudentin der nach Tausenden zählenden Gemeinde eingeschworener Partre-Fans zuzurechnen. Die 
Gelegenheit war günstig: Man kann sich bei den hoffnungslos überfüllten Veranstaltungen des begeisternden Philosophen in der Tat wunderbar persönlich kennenlernen, denn die Zuhörerinnen und Zuhörer drängen sich mitunter so eng in seinen Sälen zusammen, dass sie sich bisweilen sogar ausziehen müssen, um alle - oder doch in etwa alle - Platz finden zu können. Die Begeisterung für JeanPaul Sartre kannte in den Nachkriegsjahren in Frankreich keine Grenzen; und es wäre für die damaligen Zeitgenossen schlicht unvorstellbar gewesen, hätte man gehört, dass der so breit akklamierte Philosoph nach seinem Tod im Jahre 1980 mittlerweile seit vier Jahrzehnten in einem nicht mehr enden wollenden ,Fegefeuer' der französischen Intelligenzija schmort.

Die Zufallsbekanntschaft von Chick heißt also Alise, und sie haben sich bei einer derartigen Veranstaltung kennengelernt, wobei Chick es war, der nach Feststellung identischer Geschmacksrichtungen eine „expérience existentialiste“ machen wollte, indem er der schönen jungen Dame völlig überraschend zuflüsterte, dass er sie liebe. Die Antwort von Alise war ein „Oh“, doch ging die spontane existentialistische Erfahrung doch nicht ganz in die Hose, da Alise sich nicht in ihr Wunderland zurückzog, sondern den jungen Ingenieur zur gemeinsamen Partre-Lektüre mit auf die Bude nahm. Wenn Sie meiner Vorlesung über LiebeLesen gefolgt sind, dann wissen Sie, wie eine solche gemeinsame Lektüre weitergeht und wo sie seit Dantes Paolo und Francesca endet. Sie merken schon: Literatur (unter Einschluss der Philosophie) verbindet! ${ }^{3}$

Das achtundzwanzigste Kapitel enthält die unvergessliche Darstellung eines öffentlichen Vortrags von Partre; so sollten wir nicht darauf verzichten, es gleich an dieser Stelle miteinzubauen und zu analysieren. Als unbedingter Sartre-Fan ist Chick natürlich schon seit dem Vorabend im entsprechenden Saal und muss nicht wie viele andere sein Leben aufs Spiel setzen, um durch Fallschirmabsprung, durch die Kanalisation, durch das Drucken gefälschter Einladungskarten oder viele weitere Tricks in den Vortragssaal zu gelangen. Ich erspare Ihnen die Einzelheiten, bei denen allerdings schon die brutale, grausame Dimension des Lebens in dieser letztlich in einem fiktiven Paris angesiedelten Welt zum Ausdruck kommt. Denn bereits im Vorfeld des Vortrags werden Dutzende von Menschen zu Tode kommen.

Konzentrieren wir uns auf den Auftritt und einige wenige Vorkommnisse bei Sartres oder Partres Vortrag! Vergessen wir dabei nicht, dass wir nicht in der Loge der Duchesse de Bovouard sind, sondern uns noch in der Loge des kleinen Chick sowie im zweiten Teil hinter der Bühne, auf der Partre liest, befinden:

3 Vgl. Ette, Ottmar: LiebeLesen, S. 6-9. 


\begin{abstract}
Aber Jean-Sol näherte sich. Auf der Straße erschallten Klänge aus Elefantenrüsseln, und Chick lehnte sich aus dem Fenster seiner Loge. In der Ferne tauchte die Silhouette von JeanSol in einer gepanzerten Kabine auf, unter ihm der raue und faltige Rücken des Elefanten, der im Lichte eines roten Scheinwerfers einfach unerhört aussah. An jeder Ecke der Kabine hielt sich ein mit einer Axt bewaffneter Eliteschütze bereit. Mit großen Schritten bahnte sich der Elefant einen Weg durch die Menge, und das dumpfe Getrampel seiner vier Pfeiler, die durch die zerdrückten Körper stampften, kam unerbittlich näher. Vor dem Tor kniete der Elefant nieder, und die Eliteschützen stiegen herab. Mit einem grazilen Sprung erschien Partre zwischen ihnen, und sie bewegten sich in Richtung Bühne, wobei sie links und rechts mit Axthieben den Weg freimachten. [...]

Glücklicherweise stürzte die Gesamtheit der Decke auf den Saal herunter, was es Isis ersparte, in die Details zu gehen. Ein dichter, dicker Staub stieg empor. Mitten im Gips krümmten sich weißliche Formen, schwankten und brachen zusammen, erstickt von der schweren Wolke, welche über den Trümmern lag. Partre hielt ein und lachte aus vollem Herzen, wobei er sich vor Glück auf die Schenkel schlug, bei diesem Abenteuer so viele engagierte Leute zu sehen. Er sog einen tiefen Schluck Staub ein und begann, wie ein Verrückter zu husten. ${ }^{4}$
\end{abstract}

Erinnern Sie sich noch an unsere avantgardistischen „Serenate“ und Happenings in der ersten Hälfte des 20. Jahrhunderts in Italien, Frankreich, der Schweiz oder Deutschland? Sie können sich dank Boris Vians - der persönlich mehr für seine „Surprise Parties“ bekannt war - erheiternden und hyperbolischen Darstellung vorstellen, wie so ein existenzialistisches Veranstaltungs-Abenteuer ausgesehen haben mag, in dessen Zentrum der französische Sonnen-Gott Partre stand. Letzterer wurde selbstverständlich stets beäugt von der Duchesse de Bovouard, gab es doch viele hübsche Mädchen, die sich (wie später die Groupies bei den Rock-Stars der sechziger Jahre) um den Philosophen scharen. Boris Vian wusste, wovon er sprach, wenn er an den Schwarm um Sartre dachte, der nun wirklich keine Schönheit war. Aber darauf kam es angesichts des geforderten Engagements bei dieser ,Aventure' auch nicht an.

Kein Mensch hört freilich auf die Worte des eminenten Philosophen, alles ist direktes körperliches Erleben - wie im Falle der großen Saaldecke, die herabbricht und viele unter sich begräbt, weil sich auch dort Fanatikerinnen und Zuschauer oberhalb der Bühne gedrängelt hatten. Partre rührt das nicht. Er ist an derlei Auftritte gewöhnt, kommt er ja gleichsam als großer Mandarin ${ }^{5}$ von Paris, von Elitesoldaten geschützt, auf einem Elefanten daher, wobei ungezählte Menschen zu Tode kommen oder zerquetscht werden, gleichsam über Leichen zu neuen phi-

4 Vian, Boris: L'écume des jours. In: Romans, nouvelles, œuvres diverses. Édition établie, présentée et annotée par Gilbert Pestureau. Paris: Le Livre de Poche / La Pochothèque 1991, S. 66 ff. 5 Vgl. zu diesen großen Mandarins in der französischen Szene auch das Buch der „Duchesse“ Beauvoir, Simone de: Les Mandarins de Paris. Paris: Gallimard 1954. 
losophischen Ufern gehend. Welch wunderbare Persiflage aus der Feder von Vian, dieses Hansdampfs in allen Gassen der französischen Kultur!

In einer Stadt, deren Konturen trotz aller Anspielungen auf Paris unklar bleiben und deren Geschichte, aktuelle Politik und allgemeine Situation nicht beleuchtet werden, spielt Partre eine wichtige, vielleicht sogar vom Staat geschützte Rolle. Denn Partre ist ein Staatsphilosoph. Er vermarktet dabei, wie noch zu zeigen sein wird, seine in unerhört schnellem Rhythmus veröffentlichten Werke - fünf Aufsätze pro Woche, eine zwanzigbändige Enzyklopädie in weniger als einem Jahr sowie vieles mehr - auf überaus geschickte Weise, wodurch Vian dezent auf die Bedeutung jener Verbindungen hinweist, die sich längst zwischen dem akademischen Feld der Philosophie und einem breiten Massenpublikum ergeben haben. Leider können wir an dieser Stelle nicht auf alle humorvollen Verhohnepiepelungen von Sartres Buchtiteln und Publikationen eingehen; besonders schön ist aber doch „La Lettre et le Néon“, eine schöne Vermischung von L'être et le néant und Les mots, das sich als ein berühmtes philosophisches Werk über die Neon-Leuchtreklamen zu erkennen gibt. Man spürt hier etwas von der Hyperbolik und dem Lachen eines Rabelais - und wohl bereits auch ein klein wenig von jener Gewalt, die sich gegen den alle Felder so beherrschenden Sartre nach seinem Tod richtete und im Grunde bis heute anhält.

Selbstverständlich sind alle Veröffentlichungen, ja selbst der unscheinbarste Huster von Jean-Sol Partre Kult. Chick gibt sein letztes Geld für eine Sammlung von Partres Büchern, Manuskripten, Varianten, Hosen, Pfeifen und anderen Reliquien aus, so dass Alise letztlich nichts anderes übrigbleibt, als Partre in dessen Kaschemme aufzusuchen, wo er wie immer schreibend gerade mit der Fertigstellung seiner großen Enzyklopädie beschäftigt ist. Chicks Freundin bittet den großen Philosophen flehentlich um Chicks willen, der sich nun endgültig ruinieren würde, um den gnädigen Verzicht auf die Publikation oder wenigstens um deren zehnjährigen Aufschub, um etwas Zeit zu gewinnen. Doch Partre hat kein Einsehen und schreibt unermüdlich weiter. So sieht sich Alice schließlich gezwungen, Partre das „Arrache-cœur“ - es gibt wenig später auch den gleichnamigen Roman Herzausreißer von Boris Vian - auf die Brust zu setzen und dem verdutzten Partre das Herz in Tetraeder-Form herauszuziehen. Das sind allesamt Szenen, wie sie auch von Alfred Jarry und seinen pataphysischen Gestalten stammen könnten. Doch wir verzeihen Alice diese Tötungsart des großen Partre: Der Tod des Philosophen erscheint allen Mitfühlenden als letzte Lösung, stürzen die Kosten, die seine verschiedenen Vermarktungsstrategien verursachen, doch die Hauptfiguren des Romans in Verzweiflung, Armut und endgültigen Ruin.

Wenn wir uns die oben zitierte Szene genauer anschauen, so erkennen wir, dass sie Teil einer Schreibstrategie Vians ist, die wir unumwunden mit Michael 
Bachtin als Karnevalisierung bezeichnen können. ${ }^{6}$ Die Akzente gerade der ernsten Dinge - wie etwa das Halten eines philosophischen Vortrags - werden so verschoben, dass sie vor der Lachkultur völlig in den Hintergrund treten. In der von Vian gestalteten Szene muss selbst Sartre alias Partre lachen, verschluckt sich allerdings grässlich dabei. Im ganzen Roman haben wir es immer wieder mit verschiedenen Formen der Populärkultur wie der sich bald schon entwickelnden Popkultur sowie mit der sich herausbildenden Massenkultur zu tun. Erwähnt seien hier nur das Hollywood-Kino, der Abenteuerroman, die populäre Jazzmusik, aber auch skurrile Tanzformen wie insbesondere der „Biglemoi“, ein eindeutig erotischer Tanz, als dessen Ergebnis vor neunzehn Jahren Alise selbst vor dem Leser erstand. Wir könnten diesen Tanz, der gewiss etwas mit „Beagle“ zu tun hat, frei übersetzen als „Haschmichtanz“.

Auch das Radio hat seinen festen und wichtigen Platz in diesem Panorama kultureller Medien, wobei die Welt seriöser Sendungen oftmals urkomisch auf den Kopf gestellt wird. So erscheint die Theorie des Existenzialismus letztlich als große Mixtur, in der Reines und Überflüssiges explizit zu einem genießbaren Gebräu vermengt werden. Ausgerechnet die zentralen Begriffe des Existenzialismus - wie etwa „choix“ oder „engagement“ - werden in solche Zusammenhänge gerückt, dass sie ihren Wert als seriöse Philosopheme völlig verlieren, um in ein geradezu absurdes Theater überführt zu werden.

Auch in der oben gewählten Passage aus Vians L'écume des jours wird der für Sartres Philosophie enorm wichtige Begriff des „Engagements“ unverkennbar verhohnepiepelt. Noch stärker ist dies bei dem Verweis darauf der Fall, dass Nicolas, der „Präsident des Philosophischen Hausbediensteten-Zirkels“ („Président du Cercle philosophique des gens de maison de l'arrondissement“) ist. Es handelt sich um eine Organisation, die über weitaus mehr Renommee als etwa das Collège de France verfügt und die Problematik erörtern lässt, welche Beziehungen es zwischen dem Engagement-Begriff Partres, dem Engagement der kolonialen Truppen und dem Engagement, also der Einstellung, von Hausbediensteten gibt. Jean-Sol Partre hat wenig Nachsicht mit dem sich an seinen Werken ruinierenden Chick, habe sich dieser doch in seinem Sammlertun auf einen „choix“ festgelegt, was vollständig sein individuelles und menschliches Recht sei.

Dergestalt durchziehen den kleinen Roman Vians ständig Anspielungen auf Theoreme und Philosopheme, die explizit dem Existenzialismus zugeordnet werden und aus der Feder Partres oder aber der Duchesse de Bovouard stammen. Es muss Vian einen ungeheuren Spaß gemacht haben, die Seriosität des Philoso-

6 Vgl. etwa den deutschsprachigen Band von Bachtin, Michael: Literatur und Karneval. Zur Romantheorie und Lachkultur. Müncheen: Carl Hanser Verlag 1969. 
phischen dem populären Lachen auszusetzen, das nichts mehr von der Ernsthaftigkeit des Akademischen bestehen lässt: Die Philosophie ist hier ein Diskurs wie jeder andere und kann kein höheres Recht auf Welterklärung einklagen. Es ist das Lachen Alfred Jarrys, das sich in diesen pataphysischen Betrachtungen lautstark Bahn bricht. Damit erfolgt auch auf dieser Ebene eine Karnevalisierung der Begriffe, die von Boris Vian sozusagen das Narrenkostüm übergezogen bekommen und durch die Seiten von L'écume des jours als unseriöse Lachfragmente promenieren. So werden die Elemente einer Hoch- und einer Massenkultur miteinander vermischt, die Grenzen zwischen beiden Ebenen überschritten, die Kluft geschlossen. Leslie Fiedler hatte seine postmoderne Freude daran.

Der erste Teil des Romans spielt in einer bezaubernden Atmosphäre des Lichts, der Leichtigkeit und des Lebens in einer Welt, die dann jedoch sukzessive verdunkelt, immer schwerer und enger wird und schließlich zum unausweichlichen Tode führt. Den Wendepunkt des Romans bildet dabei die Hochzeitsszenerie von Colin und Chloé in der Kirche, wo Chloé zum ersten Mal hustet. Ihre zunächst nur als leicht erscheinende Erkrankung erweist sich bald schon als Krankheit zum Tode, die wie bei allen romantischen Heldinnen - die hier natürlich gleich mitaufgegabelt werden - von innen kommt und zumeist konvulsiv ist, wie wir aus einer langen Literaturgeschichte kränkelnder Protagonistinnen wissen.

Doch bis es zu Hochzeit und finaler Erkrankung kommt, sind noch viele Abenteuer zu bestehen, von denen das wichtigste zweifellos das der Liebe ist. Denn Colin kommt nach der Bekanntschaft Chicks mit Alise, in die sich dessen hübscher Freund ebenfalls verguckt, unter Druck, da er möglichst schnell ebenfalls eine Freundin besitzen möchte, was natürlich rasch gelingt. Dabei fehlen auch in diesem ersten Teil keineswegs die brutalen und schrecklichen Ereignisse, die allerdings in heiterem Ton und mit der größten Selbstverständlichkeit berichtet werden. Denn noch ist die Welt lichtvoll, lächelnd und leicht.

So kommt es beim Schlittschuhlaufen zu einem großen Unfall, als Colin am anderen Ende der Eissporthalle des Molitor seine Freunde Chick und Alise erkennt, zu ihnen fährt, aber dabei nicht bedenkt, dass er die obligatorische Kreisbewegung aller anderen Schlittschuhläufer^innen behindern wird. Es kommt zu einer fürchterlichen Massenkarambolage, bei der viele, nicht aber die Freunde Colins, in Stücke gerissen werden und fatal auf dem Eis verenden. Die Aufräumarbeiten werden zügig durchgeführt, es wird höchstens noch (wie in einem anderen Falle auch) ein Kreuz aus Eis aufgestellt, das schnell wieder wegschmilzt und die Leichenteile kommen in die große Falltür, die „trappe“, wie es wohl mit einer Anspielung auf Alfred Jarrys Ubu Roi heißt. Die intertextuellen Bezüge zu diesem Vorläufer der historischen Avantgarden und in dessen Nachfolge speziell auch zum Surrealismus sind derart zahlreich, dass man von einer offensichtlichen Einschreibung in diese literarische Traditionslinie sprechen 
kann. Doch sollten wir an dieser Stelle unsere Besprechung des ersten RomanTeils weiter fortsetzen!

Seit Colin Alise gesehen hat, kann er an nichts anderes als an Nicolas' schöne Nichte oder höchstens noch an Frauen überhaupt denken. Als er zu einem Empfang aus Anlass des Geburtstages eines Hundes geht, schließt sich seine Wohnungstür hinter ihm mit dem Geräusch einer nackten Hand auf einem nackten Po, die Haustür nicht weniger unkeusch mit dem Geräusch eines Kusses auf einer nackten Schulter. Schon zuvor hatte er beim Heben seines Zeigefingers in die Luft gespürt, dass Liebe in der Luft liegt - sein Zeigefinger hatte einfach zu brennen angefangen. Dieses literarische Verfahren, idiomatische Redewendungen wörtlich zu nehmen und - „exécuter une ordonnance“ - eine Ordonnanz wirklich zu exekutieren, ist direkt von den französischen Surrealisten geborgt und leistet Vian immer wieder gute Dienste. Auch auf dieser Ebene zeigt sich die Präsenz der historischen Avantgarden und ihrer Vorläufer.

Mit einem solchermaßen geschärften Bewusstsein ausgestattet, taumelt Colin hinter zwei hochhackigen Schühchen, wenig blickdichten Strumpfhosen und einem ultrakurzen Rock mehr recht als schlecht die Treppe zum Empfang hinauf, so dass es nur eine Frage weniger Minuten ist, bis Colin - aller Ungeschicklichkeiten zum Trotz - seine Chloé kennenlernt. Denn Colin ist gegen die „concupiscentia oculorum“ nicht gefeit. Mit seiner hübschen Chloé wird er bald einen surrealistischen Bummel durch Paris antreten, bei dem eine kleine rosarote Wolke die beiden Verliebten einhüllt, in der es schön warm ist und nach Zucker duftet, aus der man die Menschen beobachten, aber selbst nicht gesehen werden kann. Wenn man sich da nicht unsterblich verliebt ...! So werden Chloé und Colin bald schon ein glückliches Liebespaar, das gemeinsam Hochzeitspläne häkelt.

Der romaneske Text besitzt im ersten Teil eine grundlegend ambivalente und spielerische Struktur, indem zum einen Verfahren wie Versatzstücke des Surrealismus und zugleich des französischen Existenzialismus munter und bunt miteinander vermischt werden. Zum anderen handelt es sich aber auch um ein literarisches Spiel mit Märchen und populären Erzählformen, mit Beschreibungsweisen ausschließlich weiblicher Körperlichkeit und Objekthaftigkeit, mit USamerikanischer Jazzmusik und populärkulturellen Formen, in denen sich die geneigte Leserschaft sehr leicht verfängt. Das Ludische und miteinander über alle Grenzziehungen hinweg Vermischende sind zweifellos die vorherrschenden Bestandteile eines Schreibens, das ohne Zweifel beim Publikum auf Lesegenuss abzielt.

Dann aber beginnt die Welt nach der Hochzeit Chloés und Colins sich wortwörtlich zu verfinstern und immer enger zu werden. Auf der Hochzeitsreise kommen die sich glücklich Liebenden an den heißen Kupferminen vorbei, wo sie von Wesen abfällig angestarrt werden, welche die beiden zunächst nicht als Men- 
schen erkennen. Dies erinnert jede ${ }^{\star} n$ französische ${ }^{\star} n$ Leser ${ }^{\star}$ in an jene berühmte Szene bei Jean de La Bruyère, in welcher die Bauern auf dem Felde zunächst nicht als Menschen, sondern vielmehr als Tiere erkannt werden, bevor sie ein menschliches Antlitz zeigen. Plötzlich wird in aller Brutalität deutlich, dass es Menschen gibt, die arbeiten, und zwar unter absolut unmenschlichen und ausbeuterischen Bedingungen. Diese Szene findet sich zu Beginn des zweiten Teiles von L'écume des jours, und sie ist mit dem Hinweis gekoppelt, dass man diesen Arbeitern gesagt habe, ihre Arbeit sei gut und wichtig, so dass sie nicht nur wie die Verrückten arbeiten, sondern auch all jene verachten, die ihrerseits nicht arbeiten wollen.

Boris Vian gelingt es auf spielerische und fast beiläufige Weise, die Komplexität eines globalwirtschaftlichen Systems aufscheinen zu lassen, in welchem die einen ihr privilegiertes Leben führen, während die anderen in ausbeuterischen Tätigkeiten fast wie Tiere gehalten werden. Dass es sich hierbei um eine Kritik am auf Ungleichheit basierenden kapitalistischen System der Weltwirtschaft handelt, steht außer Frage. Für Colin freilich ist die Sache klar: Diese Menschen haben geglaubt, was man ihnen gesagt hat, also sind sie schlicht dumm, einfältig und damit selbst schuld an ihrem Schicksal! In dieser Szene kommt vielleicht zum ersten Mal in aller Dringlichkeit ein klar geformtes Ideologem in den Text, das im zweiten Teil zusammen mit der Kritik am kapitalistischen Wirtschaftssystem immer wieder abgearbeitet wird: der Kampf gegen den und die Befreiung vom bürgerlichen Wert der Arbeit.

Vergleichbar mit dieser ideologiekritischen Passage ist eine andere Stelle aus dem zweiten Teil, wo im Kapitel 51 deutlich Boris Vians antimilitaristische Position, kaum vermittelt durch die Erzählerfigur, zum Tragen kommt. Colin muss mittlerweile selbst arbeiten, weil sein ererbtes Geld fast vollständig aufgebraucht ist. So hat er sich beim Dienst für das Vaterland gemeldet. Doch seine Aufgabe ist nicht einfach: Er soll ganz einfach dafür sorgen, dass Gewehrläufe wachsen. Schauen wir uns einmal näher die Einweisung Colins an seiner neuen Arbeitsstelle an, denn sie klingt uns surrealistisch vertraut:

Die Erde ist steril, Sie wissen, was das bedeutet, sagte der Mann, es braucht erstklassige Materialien zur Verteidigung des Landes. Damit aber die Gewehrläufe regelgerecht und ohne jede Krümmung wachsen, braucht es - dies hat man seit langem festgestellt - menschliche Wärme. Das ist im Übrigen für alle Waffen wahr.

„Ja“, sagte Colin.

„Sie machen ein Dutzend kleine Löcher in die Erde“, sagte der Mann, „mittig auf Höhe des Herzens und der Leber, und Sie strecken sich auf der Erde aus, nachdem Sie sich ausgezogen haben. Sie bedecken sich mit sterilem Wollstoff, der dort liegt, und sorgen für eine vollkommen regelmäßige Wärme.“

Er hatte ein falsches Lachen und schlug sich auf den rechten Oberschenkel. 
„An den ersten zwanzig Tagen jedes Monats machte ich vierzehn davon. Ah, damals war ich noch stark! ...“

„Ja, und dann?“, fragte Colin.

„Ja und dann bleiben Sie vierundzwanzig Stunden so, und am Ende von vierundzwanzig Stunden werden die Gewehrläufe gewachsen sein.“7

Es ist leicht, hinter dieser literarischen Versuchsanordnung das surrealistische Verfahren zu erkennen, eine idiomatische Wendung wortwörtlich zu nehmen: „chair de canon.“ In dieser Passage wird buchstäblich vorgeführt, wie der Krieg die Männer braucht und ständig frisches Fleisch benötigt. Ganz selbstverständlich wird deutlich, dass die Gefahr der Arbeitslosigkeit immer auch die Gefahr in sich birgt, dass Leute für den Krieg und die Kriegsindustrie gewonnen und ausgebeutet werden können, dass sie folglich ihre Kraft und Energie in einen zerstörerischen Zweck stecken, der zuallererst ihr eigenes Leben zerstört. Wir können an derlei Stellen sehr deutlich jene pazifistische Haltung erkennen, die Boris Vian im Nachkriegsfrankreich zur Zielscheibe aller Patrioten machte.

Nun, die Menschen altern schnell in diesem Geschäft, Gewehrläufe wachsen zu lassen, so wie übrigens bei Vian alle Figuren schnell altern, welche hart arbeiten müssen und eine entfremdete Arbeit leisten - wenn sie nicht gleich daran sterben. In jedem Falle können Sie an derlei Passagen schon absehen, was Vian nach dem Skandalerfolg von J'irai cracher sur vos tombes, auf den ich noch kurz eingehen will - einige Jahre später einen weiteren Skandalerfolg einbrachte: seine pazifistischen Chansons wie Le Déserteur, in denen er klare Stellung bezog gegen Krieg, Kriegsgewinnler und Militarismus in seinen allgemeinsten Formen. Wir befinden uns in einer Zeit kurz nach der Befreiung Frankreichs durch die Armeen der Alliierten von der Pest der Nationalsozialisten. Sie sollten sich einmal zuhause Vians Chanson Le Déserteur oder ein anderes seiner zahlreichen Lieder anhören, in welchen er sich über die Kriegsgewinnler und Waffenverkäufer, von denen es auch in Deutschland allzu viele gibt, lustig macht und sie direkt anklagt ...

Doch kehren wir zum eigentlichen Handlungsfaden von Boris Vians Roman zurück! In die Liebesgeschichte der beiden Protagonisten Colin und Chloé sind viele Züge von Märchen und Kindergeschichten, aber selbstverständlich auch der antiken Liebesgeschichte um Daphnis und Chloe eingewoben, zusammen mit einigen Verweisen auf Science-Fiction-Literatur, für die sich der Verfasser wohl als einer der ersten in Frankreich stark machte. Doch die Farben des Romans wechseln: von einer rosaroten Tönung vor der Hochzeit zu einer metallisch-dunkelgrauen Tönung nach der Hochzeit, welche die Wasserscheide der gesamten

7 Vian, Boris: L'écume des jours, S. 130. 
Handlung bildet. Beispielsweise ist das erste Rendezvous von Colin und Chloé in die Farbe rosarot getaucht, eben wie erwähnt eine kleine rosarote Wolke, in der es schön warm und kuschelig ist, zuckrig riecht, aus der heraus man sehen kann ohne gesehen $\mathrm{zu}$ werden und welche die beiden Liebenden umgibt und sicher einhüllt.

Von der Geschichte dieser beiden erfährt die Leserschaft freilich nur sehr wenig, so wie überhaupt die Geschichte als Historie zumeist ausgespart bleibt. Boris Vians Kunst ist - insbesondere in diesem Roman - eine Kunst der Oberfläche ohne historische Tiefe: Und ich meine das nicht als Wertung, sondern beschreibend, um Sie zugleich auf diese Dimension des Schreibens im Zeichen der Postmoderne aufmerksam zu machen. Seine Figuren, von denen nur der Arzt Mangemanche in einem anderen Roman wieder auftaucht, besitzen im Grunde keine eigentliche Geschichte oder Herkunft; wir sehen nur von ihnen, was wir aktuell erblicken, alles andere ist uns unter der Oberfläche verborgen. Dies besitzt eine wichtige epistemologische Dimension, standen doch das 19. Jahrhundert und die erste Hälfte des 20. Jahrhunderts im Zeichen der Tiefenstrukturen. So wie Karl Marx zwischen dem Überbau und einem Unterbau unterschied, wobei alles auf diesem wirtschaftlichen Unterbau beruhte, so differenzierte auch noch Sigmund Freud zwischen der manifesten Oberfläche und den Tiefen eines dem Ich unbewussten Es, das es zu erhellen gelte. Doch ich komme auf diese Frage nach den Oberflächen und der Abwendung von den (historischen) Tiefenstrukturen zurück.

Diese Ausblendung historischer Tiefenschärfe steht ganz im Gegensatz zur damals weitgehend vorherrschenden Ästhetik, in der nicht nur im Umkreis der Temps Modernes die Geschichte zum Ort aller Legitimationen und Erklärungen, bisweilen auch zum Tribunal allen menschlichen Verhaltens und Handelns geworden war. Jean-Paul Sartres Konzepte des „engagement“ und des „choix“ sind ohne die Zentralstellung der Geschichte als legitimatorischer Instanz nicht vorstellbar - bei Boris Vian ist dies anders. Nicht etwa, dass bei ihm die Geschichte komplett ausgeblendet wäre: Wir haben ja gerade gesehen, dass er sie wie am Beispiel weltwirtschaftlicher Ausplünderung zum Teil sogar militant in sein gesamtes romaneskes Schaffen mitaufnahm, auch wenn er sich selbst nicht als politisch militanten Schriftsteller verstand! Doch in seinen Romanen ist alles polierte und raffiniert gestaltete Oberfläche, an der seine Figuren freilich selbst kleben bleiben: Hier dominieren die Riten und Zeremonien wie etwa die Hochzeitszeremonie oder Jean-Sol Partres Vortragszeremonien, ohne dass darunter etwa ein Glaube, eine Geschichte oder Überzeugung sichtbar würden. Chick beispielsweise ist kein Existenzialist, sondern ein existenzialistischer Devotionaliensammler, der wie alle Sammler darauf aus ist, dass seine Sammlung vollständig ist.

Das junge Liebespaar unternimmt einen Spaziergang durch ein seltsam entrücktes Paris, das in seinen Umrissen zwar erkennbar, aber für das aktuelle 
Lesepublikum seltsam entfremdet ist. Auch in diesem Zusammenhang dominiert eine Kunst der Oberfläche, die sich insbesondere in dem von Chloé vorgeschlagenen Schaufensterbummel dokumentiert. Gehen wir kurz mit Chloé durch dieses Pariser Passagenwerk! In einem ersten Schaufenster sieht man eine nackte Frau auf einer Matratze, die sich ihre Brüste hochbürsten lässt, wobei die Schaufensterankündigung dazu nicht recht passen mag. In einem anderen Schaufenster sehen wir eine Art Metzgertyp, der kleine Kinder öffentlich abschlachtet: Es handelt sich um eine „vitrine de propagande pour l'assistance publique“, ein Schaufenster zur Propagierung öffentlicher Wohlfahrt. Eigenartig, wie sehr die aktuelle Diskussion um massenhafte Kinderpornographie und Kindesmissbrauch dazu passen mag ...

Hier also zeigt eine staatliche Wohlfahrtsorganisation, was sie so tut: Sie schlachtet kleine Kinder ab. Colin ist unangenehm berührt, insoweit er anmerkt, dass das ganze Geld (womit wohl die Steuern gemeint sind) dafür verschwendet werde, dass man immer wieder das Schaufenster vom verspritzten Blut säubern müsse. Mehr jedoch erfahren Wir nicht. Wir werden mit Schaufenstern konfrontiert, mit Vitrinen, hinter deren gläserner Oberfläche sich keine wirklich erfahrbare, erlebbare und begreifbare Geschichte öffnet. Und doch ist diese Passage auch ein Beispiel dafür, dass sich das Element der Grausamkeit, das diesem Roman im Zusammenspiel mit der Liebesgeschichte ein so eigenes Gepräge gibt, auch schon im ersten Teil des Erzähltextes präsent ist.

Auch in ihm gibt es Brutalität und Szenen der Grausamkeit: Die jungen Liebenden sind nur zu diesem Zeitpunkt noch nicht selbst davon betroffen. Auch ein drittes und letztes Schaufenster ist gleichsam dekontextualisiert und geschichtslos: Man sieht einen großen dicken Bauch, in welchem Colin den Bauch seines früheren Kochs erkennt. Dieses Element des zerstückelten Körpers, das häufig im Roman vorkommt und diesen geradezu leitmotivisch durchzieht, ist dabei unverkennbar surrealistischer Herkunft, wobei der französische Psychoanalytiker Jacques Lacan wenige Jahre später die Theorie zum „corps morcelé“, dem zerstückelten Körper, nachlieferte. Zugleich haben wir damit die Herkunft zumindest eines Teils der Grausamkeit ausgemacht, die sich in L'écume des jours beobachten lässt, jener Grausamkeit, die wir schon bei Alfred Jarry hatten beobachten können. Mit unzähligen Fäden ist das lilterarische Werk Boris Vians mit den historischen Avantgarden, Antonin Artauds „Theater der Grausamkeit“, dem „Théâtre de la cruauté“, aber auch prospektiv mit dem „Absurden Theater“ verknüpft. Nur ist bei Vian, dem begeisterten Mitglied des Collège de Pataphysique und Wallfahrer auf den Spuren Alfred Jarrys, die Beziehung zur Wirkkraft derartiger Bilder des Grausamen eine andere. Denn er will mit seinen Bildern nicht „épater le bourgeois“, er will nicht schockieren: Seine Bilderwelt ist gleichsam in sich zurückgenommen, sie springt ihren Leser oder Betrachter nicht an, sondern 
präsentiert sich ihm als glatte, polierte Oberfläche in einer Selbstverständlichkeit, die eine ganz eigene Welt mit eigenen Gesetzen produziert und projiziert.

Dies ist nicht mehr die Welt der Surrealisten, die mit dem Revolver in der Hand auf die Straße hinausdrängt und Schluss machen will mit der Institution Kunst, sie in einem radikalen Bruch öffnen will auf das Leben, so wie wir dies wiederholt in den unterschiedlichsten Manifesten der europäischen und insbesondere westeuropäischen historischen Avantgarden immer wieder präsentiert bekamen. Vielmehr handelt es sich um eine Kunst, die gerade dadurch eine eigene, von der alltäglichen Lebenswelt abgetrennte Welt erzeugt, dass in ihr vollständig eigene Gesetze herrschen, eine ästhetische Welt, die ihre Leserschaft direkt gefangen nimmt, sie also gerade nicht auf die Straße hinausjagt, sondern im Bereich des Kunstwerkes halten will. Man könnte sagen, dass Boris Vians Kunst nicht explosiv und zentrifugal, sondern eher implosiv und zentripetal orientiert ist. Diese vollständige Welt freilich löst sich am Ende auf, genauer noch: Sie implodiert ohne Knall, ohne Bruch und Explosion. Sie wird einfach immer enger, bis sie sich auf einen einzigen Punkt zurückgezogen hat: den Schlusspunkt des gesamten Romans.

Das zweite Liebespaar, eigentlich das chronologisch gesehen erste, nämlich Alise und Chick, ist im Grunde ein „ménage à trois“. Alise, deren Name natürlich auf Alice in Wonderland anspielt und diese Dimension intertextuell mit hineinbringt, ist ebenso wie Chick von den Büchern und der Figur Partres begeistert. Doch liebt sie Chick mehr als Partre, wie sie im fünfzehnten Kapitel sagt, und hört daher anders als ihr Liebhaber mit dem Sammeln auf. Für Chick hingegen gilt der Umkehrschluss: Er liebt Partre mehr als Alise. Daher ruiniert er nicht nur sein Leben, sondern auch das von Alise und zumindest mittelbar das Leben der anderen Romanfiguren.

Bereits im ersten Teil des Romans beginnt sich eine Pathologie des Sammlers aufzuzeigen, die im weiteren Verlauf des Textes immer groteskere Züge annimmt. Dabei spielt auch bei Chick die glänzende Oberfläche eine entscheidende Rolle. Denn ihn interessieren die Inhalte der Bücher Partres nur wenig oder gar nicht: Er ist vor allem an ihrem Äußeren und am Besitz dieser materiellen Oberflächen interessiert. Er sammelt leidenschaftlich alle ihre verschiedenen Ausgaben, in Schweinsleder oder in „Ekel-Haut“ gebunden (wie es in Anspielung auf Sartres La Nausée heißt). Darüber hinaus hortet er Manuskripte, Schmierzettel, aber auch die angenagten Pfeifen, Hosen oder Hemden Partres, die er über seine spezialisierten Buchhändler für teures Geld erstehen kann. Bei Chick ist das Sammeln nicht dilettantisch, sondern wahrhaft pathologisch.

Schon in Kapitel 12 wird beispielsweise eine Partre-Ausgabe auf ungezahntem Klopapier erwähnt: Sie merken, wie weit textextern Imaginationskraft und Humor Boris Vians gehen und wie weit textintern Sammelleidenschaft und Pathologie 
des Sammlers Chick reichen. Aber selbstverständlich konstatieren wir auch eine klare Kritik an Sartre, den Erfolg seiner Schriften mit allen kommerziellen Mitteln noch zu verstärken. Von alledem bleibt am Ende nichts übrig: Chick wird wegen seiner Steuerschulden mit Hilfe eines „Egalisateur“, eines Gleichmachers also, am Fuß seines liebsten und teuersten Buchregals erschossen, seine private Bibliothek kurze Zeit später ein Raub der Flammen.

Wie wir sahen, ist in all dem eine hyperbolische Kritik an Sartre untergebracht, was diesen jedoch nicht daran hinderte, zumindest nach außen hin seiner Bewunderung für das Buch Ausdruck zu verleihen. Nun gut, wenn der Partre von Boris Vians Roman geschäftstüchtig ist, dann kann es ja vielleicht auch der reale Sartre der Temps Modernes gewesen sein, wo einzelne Kapitel dieses Bandes zum ersten Mal erschienen. Vergessen wir aber auch nicht, dass ähnlich wie bei Jorge Luis Borges - aber gewiss nicht zum ersten Male in der Literaturgeschichte - die Präsenz der Bibliothek sowohl auf ästhetischer als auch auf Inhaltsebene breiten Raum einnimmt. Gesammelt wird nicht irgendwas, sondern vorwiegend Bücher und Manuskripte.

So wie der Roman selbst eine Vielzahl intertextueller Beziehungen $\mathrm{zu}$ anderen Büchern herstellt und sich in ein Universum der Texte integriert, so bildet das Sammeln von Büchern eine tendenziell unabschließbare Bibliothek heraus, als deren Krönung nicht anders als bei Jorge Luis Borges eine Enzyklopädie erscheint. Natürlich ist es nicht die Encyclopaedia Britannica, aber immerhin doch die „Encyclopédie de la Nausée“ in nicht weniger als zwanzig Bänden, von Partre eigenhändig verfasst. Der Aufschwung der Sammelleidenschaft im Zeichen der Postmoderne und wirtschaftlich günstiger Bedingungen sei hier nur erwähnt und ohne weitere Erläuterungen mit dem verstärkten Aufblühen von Sammlungen und Museen in Verbindung gebracht, wie dies in der zweiten Hälfte des 20. Jahrhunderts weltweit sichtbar wurde. Von weitaus größerem Gewicht scheint mir das Selbstverständnis einer Literatur zu sein, die sich selbst auch als Archiv versteht, als eine Art Enzyklopädie in Aktion, die sich ständig erweitert und in immer neuen Konstellationen des Wissens auftritt. Gewiss ist auch diese Vorstellung nicht auf die Literaturen im Zeichen der Postmoderne beschränkt, erhält in diesem Kontext aber doch eine überaus große Bedeutung und Relevanz. Denn die Herausstellung von Bibliotheken und Privatarchiven beinhaltet die Vergleichzeitigung allen Wissens im interaktiven Speicher eben jenes Textes, den das Lesepublikum gerade liest.

Der in diesem Falle uneigennützige Colin, der wesentlich reicher ist als Chick, schlägt diesem vor, ihm ein Viertel seines Vermögens von insgesamt einhunderttausend Doublezons zu schenken, damit Alise und Chick heiraten können. Chick nimmt das Geschenk gerne an, verwendet es aber als pathologischer Sammler für seine Sammelleidenschaft oder, wie wir auch sagen könnten, für seinen „ménage 
à trois“ um Partre. Es ist also nur logisch, dass Alise letzteren schließlich - wenn auch zu spät - umbringen muss.

Unterdessen wird Colins eigenes Vermögen, das zu Beginn des Romans noch unerschöpflich schien, ebenso wie seine ganze Welt immer kleiner: Alles schrumpft zusammen aufgrund der großen Ausgaben für die Hochzeitsfeier. Vor allem reduziert sich das Geld aber wegen Chloés Erkrankung, die - wie sich bald herausstellt - eine Seerose in der Lunge hat, welche nur dadurch bekämpft werden kann, dass ständig frische Blumen an ihr Krankenlager gebracht werden. Nun, das kostet! Die Unsummen von Geld ruinieren Colin, ohne dass etwas gegen die fortschreitende Krankheit hätte getan werden können.

Das Schrumpfen der Welt Colins verläuft mithin parallel zu dem seines Reichtums, und die Prozessualität des Schrumpfens erinnert uns an einen anderen wichtigen Roman der französischen Literaturgeschichte: Honoré de Balzacs La Peau de chagrin. Das Chagrinleder ermöglicht seinem Besitzer die Verwirklichung von Wünschen und Begierden, schrumpft aber dabei immer mehr zusammen und zeigt damit zugleich das solchermaßen beschleunigte Ende der Lebenszeit seines Besitzers an. Auf dieser Ebene findet sich ein deutlicher Parallelismus, eine klare intertextuelle Beziehung zu diesem vielleicht philosophischsten Roman aus der Comédie humaine. La Peau de chagrin darf vielleicht sogar als der am meisten goutierte Roman Balzacs in Zeiten der Postmoderne gelten. ${ }^{8}$

Dies liegt nicht nur daran, dass es explizite Bezüge zwischen La Peau de chagrin und jenem Kultroman der Postmoderne aus dem 18. Jahrhundert nämlich Laurence Sternes Tristram Shandy - gibt, sondern mehr noch, dass sich das Chagrinleder just in einem Antiquariat fand, in dem Kunstwerke und Objekte der unterschiedlichsten Zeiten zugleich gegenwärtig, also vergleichzeitigt sind. Wir können all diesen intertextuellen Bezügen im thematischen Rahmen unserer Vorlesung nicht nachgehen, doch scheinen sie mir für Boris Vians Roman von großer Relevanz zu sein und darüber hinaus jenseits der direkten intertextuellen Relationen auch auf eine spezifische Sensibilität gegenüber derartigen Themenstellungen zu verweisen, die - wie wir langsam erkennen - für die Literaturen im Zeichen der Postmoderne charakteristisch ist.

Der dunkle und tragische zweite Teil ist im ersten schon angelegt, worauf schon die Tatsache hinweist, dass Colin am Tag vor seiner Hochzeit eine Unmenge Blumen für Chloé bestellt, dass Chloé direkt nach der Hochzeit zu husten beginnt

8 Vgl. auch Ette, Ottmar: LebensMitte(l) Literatur. Vom Lesen des Lebens als Mittel des Lebens. Überlegungen im Anschluß an Honoré de Balzacs „La Peau de chagrin“. In: Ette, Ottmar / Sánchez, Yvette / Sellier, Veronika (Hg.): LebensMittel. Essen und Trinken in den Künsten und Kulturen. Zürich: diaphanes 2013, S. 21-46. 
und viele weitere Indizien darauf hinweisen, dass es sich keineswegs um eine radikale Zweiteilung des Romans handelt. Das Böse hat die positiven, jungen und optimistischen Protagonisten nur noch nicht richtig im Griff. Doch es wird zupacken, auch wenn sie noch nichts davon ahnen. Mit umfangreichen und kostspieligen Vorbereitungen wird das große Hochzeitsfest gestaltet, wobei es in diesem Zusammenhang nicht um Inhalte wie etwa Glaube, Religiosität oder auch nur um Ethik, sondern ausschließlich um blitzblanke Oberflächen, Riten und Zeremonien geht. Der aus der „Sacristoche“ kommende „Religieux“, sein „Bedon“ und ein „Chuiche“ werden ausschließlich für ihre Performanz bezahlt, wie sie auch am Ende des Romans, dann allerdings kärglich, für die fällige Beerdigung entlohnt werden.

Damit ergibt sich ein in toto symmetrischer Aufbau des Romans: Am Ende der ersten Hälfte steht die Performanz einer Reichen-Hochzeit, während am Ende der zweiten jene einer Armen-Beerdigung steht. Nach den Vorbereitungen ziehen sich die drei Kirchenmänner ihre Fallschirme über und springen in den gewaltigen Kircheninnenraum hinunter, wo sie sanft landen. Auch hier ist der Innenraum in seiner Größe proportional zum Einsatz und Vorhandensein der Geldmittel: Erst in der zweiten Hälfte werden Geldmittel und Räume spürbar kleiner, enger, feuchter und trauriger. Noch unmittelbar vor der Hochzeit kommen Chick und Colin an einer Buchhandlung vorbei, in deren Auslage Chick ein Exemplar eines Partre-Bandes in kostbarer Aufmachung sieht. Er hat kein Geld, beginnt aber vor Begierde derart aus dem Mund zu triefen, dass sich auf dem Boden ein Rinnsal bildet. Colin hat ein Einsehen und gibt Chick genügend Geld, um dessen Begierde zu stillen.

Die Hochzeit beginnt und Colin wagt nicht, die wunderschön gekleidete Chloé zu küssen, da er befürchtet, ihre Aufmachung durcheinanderzubringen; doch hält er sich bei Alise und Isis schadlos. Wir dürfen daraus schließen, dass auch an dieser Stelle die schöne Oberfläche nicht zerstört, noch nicht einmal in Unordnung gebracht werden darf. Die Austauschbarkeit der Liebespartnerinnen erscheint in diesem Zusammenhang ebenso wie die Tatsache, dass die einmalige Festlegung auf eine Partnerin offenkundig von den Konventionen her zur Beibehaltung der einmal getroffenen Wahl verpflichtet. Dies besagen zumindest die für Männer geltenden Spielregeln.

So kommt es auch nie zu einer Verbindung von Daphnis alias Colin mit seiner Alise alias Alice in Wonderland. Die Geschichte kann nicht gut ausgehen. Machen wir uns kurz mit der Zeremonie vertraut, die musikalisch von der orchestralen Aufführung eines Blues, und zwar - wie Sie schon vermutet haben - mit dem Titel „Chloe“, eingerahmt wird! Das Orchester wird allerdings nicht mehr von seinem Chefdirigenten geleitet. Werfen wir einen längeren Blick auf die Zeremonie: 
Es gab einen plötzlichen dissonanten Akkord, da der Orchesterchef, der sich dem Rande zu sehr angenähert hatte, gerade ins Leere gefallen war, so dass der Vizechef die Leitung des Ensembles übernahm. In dem Augenblick, als der Chef auf den Steinplatten aufschlug, ließen sie einen anderen Akkord hören, um den Lärm des Falles zu übertönen, doch die Kirche erzitterte in ihren Grundfesten.

Colin und Chloé betrachteten verwundert die Parade der Geistlichen, des Dickbauchs und des Schweizarden, und zwei Unter-Schweizarden warteten hinten an der Kirchentüre auf den Augenblick, um ihre Hellebarden zu präsentieren. [...] Der Geistliche, der Dickbauch und der Schweizarde tanzten, nachdem sie ihre Instrumente weggeräumt hatten, derweil einen Kreistanz.

Auf dem Kirchenvorplatz führten Colin und seine Freunde eine komplizierte Bewegung aus und fanden sich hernach in bester Ordnung, um in die Kirche einzutreten: Colin mit Alise, Nicolas am Arm von Chloé, danach Chick und Isis und schließlich die Brüder Desmaret, aber diesmal Pegasus rechts und Coriolan links. Der Geistliche und seine Schergen hörten auf, sich im Kreise zu drehen, übernahmen die Führung der Prozession und alle stimmten einen gregorianischen Gesang an und rannten rasch zur Türe. Die Unter-Schweizarden ließen auf ihren Köpfen im Vorübergehen kleine Ballons aus dünnem Glas voll lustralen Wassers platzen und steckten ein brennendes Räucherstäbchen in ihre Haare, das für die Männer mit einer gelben und für die Frauen mit einer violetten Flamme brannte.

Die Wägelchen waren am Kircheneingang aufgestellt. Colin und Alise nahmen im ersten Platz und fuhren sofort los. Man gelangte in einen dunklen Gang, der nach Religion roch. Das Wägelchen fuhr mit Donnerklang auf den Schienen, und die Musik hallte lautstark nach. Am Anfang des Ganges stieß das Wägelchen eine Türe auf, bog in rechtem Winkel ab und der Heilige erschien, ganz in grünes Licht getaucht. Er machte grässliche Grimassen, und Alise schmiegte sich enger an Colin. Spinnennetze fegten ihnen durchs Gesicht und Bruchstücke eines Gebets kamen ihnen ins Gedächtnis. Die zweite Vision war die der Jungfrau, und bei der dritten, im Angesicht Gottes, der mit schwarzbuttrigem Auge nicht zufrieden aussah, fiel Colin wieder das ganze Gebet ein, so dass er es Alise sagen konnte. ${ }^{9}$

Ich habe diese Passage etwas ausführlicher zitiert, um Ihnen einen zusätzlichen Einblick in die literarischen Verfahrensweisen und den Grundton des Romans zu ermöglichen. Sie haben bemerkt, wie sich gleich zu Beginn in aller Brutalität ein Zwischenfall ereignet, der jedoch nach Möglichkeit übertüncht oder besser übertönt werden soll. Der Orchesterchef stürzt aus der großen Höhe des Kirchenschiffs ab und kommt dabei um. Schnell wischt die Schweizer Garde die Blutlache von den Steinplatten und der Geistliche wird dies später zum Anlass nehmen, dem Orchester nicht den bereits berechneten Posten für den Orchesterchef auszubezahlen, da dieser bereits vor Beginn der Aufführung verstorben sei. Auch an dieser Stelle wird jedoch versucht, geradezu mit Techniken Alfred Jarrys - nicht umsonst erscheint später der heilige in grünes Licht getaucht - die Oberfläche zu bewahren und die so schön bunte Szenerie nicht zu stören.

9 Vian, Boris: L'Ecume des jours, S. $52 \mathrm{f}$. 
Neben den Ehrenjungfrauen gibt es beim Einzug der Hochzeitsgäste auch Ehrenjungs, daneben aber auch die „Pédérastes d'honneur“, die „Ehren-Schwulen“, die bei keiner festlichen Gelegenheit fehlen dürfen. Performanz ist alles! Das Interessante ist dabei nicht zuletzt, dass die implizite Karnevalisierung der Welt des Romans in die Normalität zurückgebogen ist, um deutlich zu machen, dass in dieser Welt sehr eigene Gesetze herrschen. Letztere sind zwar von denen der Welt des Lesepublikums nicht völlig verschieden, stellen zugleich aber eine unauflösliche Mischung zwischen Traum und Realität, Imagination und Konvention, purem Spiel und bloßem Ernst dar. Genau hierin besteht der spezifische Ton, der Vians Roman grundlegend prägt und ihm eben jene spielerische und zugleich brutale Dimension verleiht, in der die Performanz, die bunte Oberfläche, in den Vordergrund rückt und logische Zusammenhänge zunehmend an Gewicht und Wichtigkeit verlieren. Die klerikalen Traditionen sind bei der Hochzeitsfeierlichkeit nicht vergessen, werden jedoch in ein schrilles Licht gezerrt, welches die Gegensätze wie die Grenzen zwischen religiösem Ritus und volkstümlicher Geisterbahn verschwimmen lassen.

Die Karnevalisierung der Religion, wie sie hier in der Mischung aus Heiligenbildchen und Geisterbahn vorgeführt wird, leitet zur Religion der Karnevalisierung über. Die Welt steht nicht einfach auf dem Kopf, sie ist auf dem Kopf richtigherum aufgestellt. Auch Sartres existentialistische Philosophie ist nicht einfach ernst und seriös: Sie wirkt vielmehr als pure Fiktion und wird - so wie Borges jegliche Philosophie als Fiktion las - erst als fiktives Spiel verstehbar und vielleicht sogar genießbar.

Die obige Szene hat in gewisser Weise Modellcharakter, denn sie versinnbildlicht als Schein und Spiel eine ganze Welt, die im Sinne Baudrillards zum Simulacrum geworden ist. Der Glaube wird simuliert, die Religion als Ritus lebbar: Die Geisterbahn bringt das Gedächtnis einer religiösen Erziehung in Schwung, die nur oberflächlich war und nur die Oberfläche aufsagbarer Sprüche und Gebete betraf. Unter dem Schein der Angst wird ein Schein von Gebet wieder hervorgekramt, ohne jede tiefe Gläubigkeit und ohne jedes tiefe Gottvertrauen. Da können die Heiligen grässliche Grimassen schneiden so viel sie wollen: Sie wirken nur noch auf einer zweidimensionalen Projektionsfläche als Bilder und Erinnerungen einer längst vergangenen Zeit. Selbst der Geistliche hat keinen geistlichen Inhalt mehr: Ihm geht es nur noch um Kommerz und Kalkül. Es ist ihm egal, ob in seiner Kirche ein Orchesterchef in die Tiefe stürzt, denn mit der Tiefe ist es ein für alle Mal vorbei - und die Blutspuren auf der Fläche der Steinplatten sind schnell wieder weggewischt.

Es entsteht - wenn Sie so wollen - eine virtuelle Welt, in der eigentlich alles nicht so ganz wahr zu sein scheint: nicht der Tod der Anderen oder der Tod überhaupt, nicht das Altern, nicht die Religion, nicht der Glaube. Alles verflüchtigt sich 
in die schöne bunte Welt der Projektionen, die ein zweidimensionales Leben vorgaukeln. Alles erscheint als virtuell und wird auf diese Weise verfügbar gemacht, bis sich diese Virtualität in der zweiten Hälfte des Romans die Protagonisten verfügbar oder gefügig macht. Denn gestorben wird schon noch in Echtzeit ...

Genau an dieser Stelle kippt die Welt der Virtualität und zeigt - und dies ist keineswegs postmodern -, dass unter ihrer schönen, noch nicht digital gepixelten Oberfläche doch noch eine weitere Wirklichkeit da ist, die ihre Kinder dann aus ihrem Second Life abholt und auffrisst. Ganz so, wie schon der Todessturz des Orchesterdirigenten nicht ganz übertönt werden konnte. Die Blutflecken betonen, dass an seinem Tod nicht zu zweifeln war, doch ihre Projektion auf die Steinplatten gleicht jeder Projektion auf einen Bildschirm: Schnell kann der wieder mit neuen Bildern aus einer Virtual Reality bestückt werden.

Die (sich andeutende) kybernetische Welt ist in Boris Vians Roman L'écume des jours noch nicht absolut geworden. Unterhalb ihrer Oberfläche scheint doch noch eine andere Welt auf, die auch den Protagonisten selbst ans Chagrin-Leder geht und ihrem Leben langsam, aber sicher nach einem langsamen Schrumpfungsprozess ein definitives Ende setzt. Die Protagonisten des Romans bezahlen einen hohen Preis dafür, dass sie so lange an das Simulacrum glaubten, hinter dem eine Realität der Steuereintreibungen, absoluter Herrschaft, kriegerischer Auseinandersetzung und radikaler kolonialer oder postkolonialer Ausbeutung sichtbar wird. Im Grunde sind sie alle in dieser Fiktion wie Colin: groß gewordene, aber noch immer sabbernde Babys, die ihr Glücklich-Sein mit dem Leben, die Performanz mit der Essenz verwechseln. Dies klingt also alles nicht mehr sehr postmodern, und Sie haben schon verstanden: Es geht mir ganz bestimmt nicht darum, Boris Vian als Postmodernen zu deklarieren und Ihnen als solchen zu verkaufen. Wir bleiben also nicht beim Schaum der Traumwelt in L'Ecume des jours stehen! Doch wir verstehen, dass sich bei Boris Vian etwas in der experimentellen Romanfiktion andeutet, was der hochtalentierte französische Künstler wohl früher als andere erkannt hat. Er weist voraus auf die baldige Allpräsenz einer virtuellen Welt, die freilich bei ihm eingehüllt ist in die reale Welt des US-amerikanischen Jazz und der bald alles überschwemmenden Massenkultur.

Es ist unmöglich, im Rahmen dieser Vorlesung auf Boris Vians L'Ecume des jours noch ausführlicher einzugehen, denn wir könnten uns viele Sitzungen lang mit diesem kurzen, aber ungeheuer dichten Roman des französischen Schriftstellers und Multitalents beschäftigen. Vians modernes und postmodernes Märchen endet in einer völligen Katastrophe, die sich ebenso langsam wie präzise einstellt und Schritt für Schritt vorrückt. Es ist eine Art Apokalypse, aber keine ,apocalypse douce“, keine sanfte Apokalypse. Es ist vielmehr eine Verdunkelung der Welt, in der die Sonne nicht mehr durch die Fensterscheiben dringt, das Geld ausgeht, das luxuriöse Leben Zug um Zug verschwindet und vor allem die beiden schönsten 
Dinge der Welt, wie sie das Vorwort nennt, also der Jazz aus New Orleans und die Liebe mit hübschen Mädchen, nicht mehr wirklich möglich sind. Was hat das Leben dann noch für einen Sinn? Die Liebenden sind krank, sterben oder bringen sich um, und die Plattenspieler, die zuvor noch die Welt mitdrehten, stehen still. Da bleibt auch der Maus am Ende des Romans nur der bitterlich erflehte Selbstmord im Rachen einer vollgefressenen und etwas maulfaulen Katze. Das Märchen ist aus!

Die Welt des Boris Vian aber begann sich nun erst recht zu drehen. Seine zweifellos produktivsten Jahre sind diejenigen unmittelbar nach Ende der Occupation, in denen er eine Vielzahl von Romanen, Krimis, Liedern, Musikstücken niederschrieb oder zur Aufführung brachte, in denen er als Romancier Skandalerfolge einheimste, als künstlerischer Direktor bei Plattenfirmen arbeitete oder als Animateur in Pariser Nachtklubs seine Fans um sich scharte. Bis heute sind seine Auftritte als Jazztrompeter legendär.

Über all seinen Schriften schwebt die Musik, die er machte, die ihn mit der Kultur der Vereinigten Staaten in engste Beziehung brachte und doch zu einem Franzosen werden ließ, wie ihn nur die unmittelbare Nachkriegszeit hervorbringen konnte. Vian war, wie ich schon betonte, ein Multitalent, das freilich nicht auf allen Gebieten gleich begabt war, aber auf allen Ebenen dieselbe Lebendigkeit und Leichtigkeit ausstrahlte. Er war vor allem ein Künstler, der seine Kunst nicht auf den Bereich der Schriftstellerei begrenzt sah, sondern die unterschiedlichsten Ausdrucksformen und Gattungen ausprobierte und Kultur keineswegs nur mit elitären Großbuchstaben schrieb. Vian war offen für populäre Kulturformen ebenso in der Musik, im Theater wie im Roman. Dies zeigen nicht nur die Anleihen bei Märchen und Science-Fiction in L'écume des jours, sondern auch seine eigenen Kriminal- und Science-Fiction-Romane. Wir können dies alles in diesem Rahmen nicht diskutieren, doch wäre es unmöglich, über Boris Vian zu sprechen, ohne zumindest kurz seinen ersten großen Skandalerfolg zu erwähnen: J'irai cracher sur vos tombes.

Dieser Roman entstand innerhalb weniger Tage im Kontext einer Wette im Sommer des Jahres 1946. Das Titelblatt verkündete jedoch nicht den Namen von Boris Vian, sondern den eines gewissen Vernon Sullivan. Uns sind diese Spiele mit den Autornamen in unserer Vorlesung schon mehrfach begegnet, so dass ich darauf nicht weiter insistieren möchte. Jedenfalls habe dieser Kriminalautor auf Grund inhaltlicher Motive seinen Roman in den USA nicht publizieren können, so dass man ihn nun in französischer Übersetzung veröffentlichen müsse.

Mit dem Roman J'irai cracher sur vos tombes beginnt eine Reihe von Sullivan-Romanen, die nach dem Paukenschlag des ersten Erfolges von Boris Vian nachfolgend verfasst und unter seinem US-amerikanischen Pseudonym publiziert wurden. Der Roman, in welchem der typisch US-amerikanische Rassismus, 
brutale Gewalt und explizite Sexualität die Hauptrolle spielen, wurde bald schon von einer Pariser Keuschheitskommission unter einem gewissen Daniel Parker (der von Vian wenig später kurzerhand in eine Romanfigur verwandelt wurde) angeklagt, was sich ganz ohne Zweifel enorm absatzfördernd auswirkte. Alle Franzosen wollten diesen inkriminierten Roman nun lesen, der Verlag druckte und druckte. Vernon Sullivans Prosatext war endgültig in aller Munde, als wenig später ein Mann in Paris seine Geliebte auf eben jene Art hinstreckte, in der der Held von J'irai cracher sur vos tombes eines seiner Opfer meuchelt. Dabei ließ der reale Mörder pikanterweise - vielleicht handelte es sich bei ihm aber auch um einen möglicherweise arbeitslosen Philologen? - Vernon Sullivans Buch auf der richtigen Seite aufgeschlagen neben seiner von ihm ermordeten Geliebten liegen. Das Maß war voll und die Justiz (heraus)gefordert!

Sie können sich leicht vorstellen, dass in allen Boulevardblättern die Suche nach dem wahren Autor (oder Mörder) begann; und nachdem Boris Vian eine geraume Zeit später seine Autorschaft eingestand, half ihm wenig, dass er beteuerte, er sei kein Mörder, sondern ein Romancier. Fortan umschwebte ihn der Geruch des Skandalträchtigen, so wie der Geruch des Todes seinen Roman J'irai cracher sur vos tombes einhüllte.

Auch wenn wir uns nur kurz mit diesem Roman beschäftigen können, der alle Ingredienzien mitbringt, welche ein zeitgenössischer US-amerikanischer Kriminalautor zusammenmixte, so sehen wir doch deutlich, wie sich Boris Vian zwar an eine Textgattung der Massenkultur heranrobbte, ohne jedoch eine Reihe von in dieser Gattung gängigen Tabuthemen zu respektieren. Mir ist die Geschichte, die blutig und katastrophal endet, weniger wichtig als die Tatsache und die Kontexte ihrer Verfertigung durch den französischen Autor. Selbstverständlich ist es so, dass in einem erfolgreichen US-amerikanischen Roman keinesfalls der gegen die schwarze Bevölkerung gerichtete Rassismus eine so starke Rolle spielen könnte und mit einem so kritischen Potenzial ausgestattet wäre. Es handelt sich folglich um ein Pastiche, das kein Pastiche sein will, und um ein „Fake“, das kein „Fake“ sein möchte. Und doch sollten Sie einmal kurz hineingerochen haben in diesen Roman mit dem spektakulären, etwas blasphemischen Titel, der im August 1946 verfasst, im November 1946 veröffentlicht und zum Bestseller des Jahres 1947 wurde.

Ich hatte Sie ja schon einmal vorgewarnt im Rahmen dieser Vorlesung, und in der Tat lässt die Darstellung erregter männlicher Körperlichkeit kaum einen anderen Schluss $\mathrm{zu}$ als den, dass auch in diesem Falle ein überzeugter und passionierter Leser des Marquis de Sade ein eigenes kreatives Betätigungsfeld gefunden hatte. Andererseits werden Sie vielleicht aus der Nachkriegssituation und ihren Hexenjagden heraus verstehen, warum die Pressekampagne für den „Prinzen Boris“ nicht ungefährlich war. Während man 1949 seinen ersten Sul- 
livan verbot, verurteilte man 1950 den Autor der ersten beiden Sullivans (der zweite trug den Titel Les morts ont tous la même peau) wegen seiner Sittenwidrigkeit, einer „outrage aux mœurs“ rechtskräftig zu einer letztlich wenig empfindlichen Strafe.

Unsere Szene stammt aus dem letzten Teil des Romans und lassen Sie mich kurz einige für uns wichtige Ereignisse zusammenfassen! Lee, der weißhäutige Held, der aber weiß, dass er schwarzes Blut in seinen Adern hat, rächt sich an den Weißen, die seinen schwarzen Bruder gelyncht hatten, weil dieser sich mit weißen Frauen einließ, gerade dadurch, dass er es ebenfalls mit weißen Frauen treibt, auf die er unwiderstehlich wirkt. Schließlich bringt er zwei rivalisierend in ihn verliebte Schwestern, die er fast gleichzeitig verführt hat, schön nacheinander um. Diese Mordszene habe ich für Sie ausgesucht. Wir sind am Ende der vorwiegend in der ersten Person Singular erzählten, ,gerahmten` Geschichte angelangt, bevor wieder eine Erzählerfigur in der dritten Person Singular das Wort ergreift:

Es fiel mir schwer, all das zu sagen. Die Worte kamen nicht von alleine. Sie war da, mit geschlossenen Augen, lag am Boden mit ihrem bis zum Bauch hochgezogenen Rock. Ich fühlte noch das Ding, das meinen Rücken hinunterlief, und meine Hand schloss sich um ihren Hals, ohne dass ich es verhindern konnte; es kam einfach; es war so stark, dass ich sie losließ und mich fast aufrichtete. Sie bekam bereits ein blaues Gesicht, aber sie rührte sich nicht. Sie hatte sich erdrosseln lassen, ohne etwas zu unternehmen. Sie musste eigentlich noch atmen. Ich habe den Revolver von Lou in meiner Tasche genommen und habe ihr zwei Kugeln in den Hals geschossen, fast mit aufgedrücktem Lauf; das Blut spritzte in dichtem Schwall heraus, kam langsam, in einzelnen Strömen, mit einem feuchten Geräusch. Von ihren Augen sah man gerade noch eine weiße Linie, die unter ihren Lidern lief; sie hatte eine Art Zucken, und ich glaube, dass es in diesem Augenblick war, dass sie starb. Ich habe sie umgedreht, um nicht länger ihr Gesicht zu sehen, und während sie noch warm war, habe ich mit ihr gemacht, was ich schon in ihrem Zimmer mit ihr gemacht hatte.

Ich bin wohl unmittelbar danach bewusstlos geworden ... ${ }^{10}$

Die in der obigen Passage geschilderte Situation gehört sicherlich zu den härteren des Genres und ist in der Tat „Hard Boiled“, doch weiß ich nicht recht, ob wir dem Roman - wie heute in den USA üblich - wirklich das Etikett „,sexually explicit“ aufkleben müssen. Recht elegant werden allzu körperliche Details ausgespart, auch wenn die Erzeugung der Bilderwelt im Leser, die Hypotypose, deshalb keineswegs geringer ausfallen dürfte. Hypotypotisch werden in uns wohl Bilder erzeugt, welche unbestreitbar eine starke Nachwirkung haben. Der Kinogänger und Drehbuchschreiber Boris Vian wusste das nur zu gut. Vielleicht ist er auch deshalb durch einen Herzinfarkt bei der Privataufführung der vehement von ihm

10 Vian, Boris: J'irai cracher sur vos tombes. Paris: France Loisirs 1979, S. 133. 
abgelehnten Verfilmung eben dieses Romans gestorben - ein sprechendes Biographem, auf das ich gleich noch einmal zurückkommen werde. J'irai cracher sur vos tombes, das ja auch die Vorlage für einen echten Mord bildete, hat also mehrere Menschenleben auf dem Gewissen.

Man könnte sehr wohl sagen, dass wir es fast mit einer Art Ritualmord zu tun haben, bei dem sich das auserwählte Opfer gar nicht wehrt. Der nachfolgende Wechsel von der ersten zur dritten Person Singular weist darauf hin, dass der Mörder uns seine Geschichte nicht mehr zu Ende erzählen kann, mit anderen Worten: dass er von der Polizei nicht nur gejagt, sondern auch erschossen wurde. Aber ähnlich wie sein Opfer stirbt auch er sicherheitshalber gleich zweimal, ebenfalls wie bei einem Ritual. Denn der Erschossene wird am Ende von den aufgebrachten weißen Dorfbewohnern noch gehängt, wie man dies mit einem Schwarzen nun einmal machen müsse. Auch dies also ein Ritualmord, der im Übrigen ganz jenem Bild der Vereinigten Staaten entsprach, wie es sich in den Zeitungen und Zeitschriften im Frankreich der Nachkriegszeit verbreitete. Man hatte die vielen schwarzen US-Soldaten bei der Befreiung Frankreichs erlebt und gesehen, dass nach dem Krieg die alte rassistische Ordnung wiederhergestellt wurde. Vielleicht auch, um den eigenen Rassismus nicht mit aller Schärfe zu sehen, räumte man dem offenkundigen Rassismus in den USA publizistisch breitesten Raum in Frankreich ein. Wir wissen heute sehr wohl, dass sich an diesen Rassismen im Grunde wenig geändert hat.

Die Geschichte Lees ist die Geschichte eines Schwarzen, der „die Linie passiert“ hat, wie der Roman es formuliert, der also für Außenstehende schlicht weiß aussieht und als Schwarzer nicht erkennbar ist. Boris Vian hatte damals gelesen, dass es mehrere Millionen derartiger „gens qui ont passé la ligne“ in den USA gab, die auf den ersten Blick nicht auffielen, auf Grund ihrer Herkunft aber dennoch diskriminiert wurden. Sie werden mir es nicht glauben, wenn ich Ihnen sage, dass zu Beginn des 20. Jahrhunderts in den USA selbst die Iren als ,nicht-weiß` galten, weil man sie für katholische Trunkenbolde hielt und nicht als ,wirkliche Weiße، akzeptierte. Derartige Hürden gibt es auch heute noch für die ,Latinos‘, die in die USA kommen wollen: Auch sie müssen sich ,rassisch' (aber eigentlich rassistisch) gleich an der Grenze deklarieren. Ich empfehle Ihnen zum Überblick über historische wie aktuelle Rassismen und Diskriminierungen in den Vereinigten Staaten die Lektüre eines Bandes von Nell Irvin Painter über die Geschichte der Weißen, die eigentlich eine Geschichte ihrer Diskriminierungen ist. ${ }^{11}$

11 Vgl. Painter, Nell Irvin: A History of White People. New York - London: W.W. Norton 2009; sowie hierzu dies.: History of the White People - Introduction. In: Ette, Ottmar / Mackenbach, Werner / Müller, Gesine / Ortiz Wallner, Alexandra (Hg.): Trans(it)Areas. Convivencias en Cen- 
Doch zurück zu unserem Roman! Auch von Boris Vian selbst ließe sich sagen, dass er jene Linie passierte, die innerhalb des Literaturbetriebs nicht nur in Frankreich geradezu unsichtbar die wahren Schriftsteller von jenen trennte und trennt, die nicht als solche zu betrachten sind. Nun, Boris Vian war ein Schriftsteller, der auf beiden Seiten der Linie zwischen der Hochkultur, der ,Schönen Literatur ' und der Massenkultur des Kriminalromans lebte.

Doch à titre d'anecdote muss ich doch noch nachholen, was damals die zahlreichen Moralisten in Frankreich besänftigt haben dürfte. Denn es hatte zu ihrer Beruhigung noch nicht ausgereicht, dass Lee am Ende für seine Schandtaten nacheinander erschossen und gehenkt wurde, so dass doch immerhin dem Prinzip der ausgleichenden Gerechtigkeit - zumindest scheinbar - Genüge getan war. Die Logik der Massenkultur galt für das Genre, dessen sich Vian in diesem Roman bedient hatte. J'irai cracher sur vos tombes wurde zu einem Bestseller, und so lag schon zum damaligen Zeitpunkt die Idee einer knackigen Verfilmung nahe. Boris Vian konnte sich sträuben wie er wollte, zu verlockend war für die beteiligten Verlage und Konzerne das einträgliche Geschäft mit dem Skandalroman. Wobei wir hier zwischen der Leichtindustrie der Verlage im Bereich Höhenkammliteratur und der Schwerindustrie der Filmkonsortien unterscheiden müssen, die nach ganz anderen Kriterien operierten. So einfach war das Spiel diesseits und jenseits der Linie zwischen Elite- und Massenkultur offenkundig nicht!

Einige Freunde überredeten Vian, zu einer ersten Vorabaufführung einiger Szenen zu gehen, die sich der französische Autor wohl einigermaßen angewidert anschaute, so dass er beschloss, gegen die Verfilmung vorzugehen oder zumindest seinen Namen nicht für ein solches Projekt herzugeben. Doch zu einem im Bereich des Möglichen liegenden Prozess kam es, wie wir wissen, nicht mehr: Boris Vian starb am 23. Juni 1959 noch im Kinosaal. Eine wirkliche Performanz, könnte man kaltblütig sagen, auf jeden Fall auch dies ein Skandal, der noch seinen Tod überschattete: J'irai cracher sur vos tombes wirft ein eigenartiges Licht auf bestimmte Todesszenen in Vians so ganz anderem Roman L'écume des jours.

Das Überschreiten der Linie aber war genau das, was Boris Vian aus heutiger Sicht mit Positionen der Postmoderne verbindet: Cross the Border, Close the Gap. Denn es wäre Vian nicht im Traum eingefallen, sich an die ungeschriebenen Regeln des traditionellen Literaturbetriebs zu halten. Doch man konnte dieses vielseitige und allzu früh verstorbene Talent weder den Existenzialisten noch den Surrealisten zuordnen, so wie wir ihn nun auch nicht post mortem in einen Postmodernen verwandeln wollen. Sein vieldeutiger Umgang mit Kultur wie seine

troamérica y el Caribe. Un simposio transareal. Berlin: edition tranvia - Verlag Walter Frey 2011, S. 173-175. 
kulturellen Praktiken unterschieden ihn grundlegend von Positionen, die erstere als den abgegrenzten Bezirk einer Elite sahen, in deren Bereich, deren „chasse gardée“ man ungeprüft nicht eindringen durfte.

Mit den Begrifflichkeiten des Feldsoziologen Pierre Bourdieu könnten wir sagen, dass Boris Vian sowohl im „champ de production restreinte“ wie auch im Feld der Massenkultur arbeitete, ebenso in der „Schönen Literatur“ wie im Jazz oder im französischen Chanson. Er schrieb Kriminalromane nach US-amerikanischem Muster ebenso wie Science-Fiction und war in der Schallplattenindustrie erfolgreich. Diese neue Auffassung der Kultur, dieses neuartige Verständnis von Kultur, das durchaus etwas von den Surrealisten - und zwar genau ein wenig Avantgarde - ererbt hat, zielte gleichwohl nicht vorrangig auf die Erfahrung des Schocks, sondern auf sanftere Formen der Vermittlung. Boris Vian hat diesen Schock der historischen Avantgarden vielmehr in eine Welt der Selbstverständlichkeit und Performanz integriert, die in ihrer Gestaltungsvielfalt vieles mit jenen Charakteristika der Postmoderne gemein hat, mit der wir uns im Folgenden wieder im transatlantischen Spiel zwischen den Amerikas und Europa beschäftigen wollen. 